\title{
Subsurface oceanic structure associated with atmospheric convectively coupled equatorial Kelvin waves in the eastern Indian Ocean
}

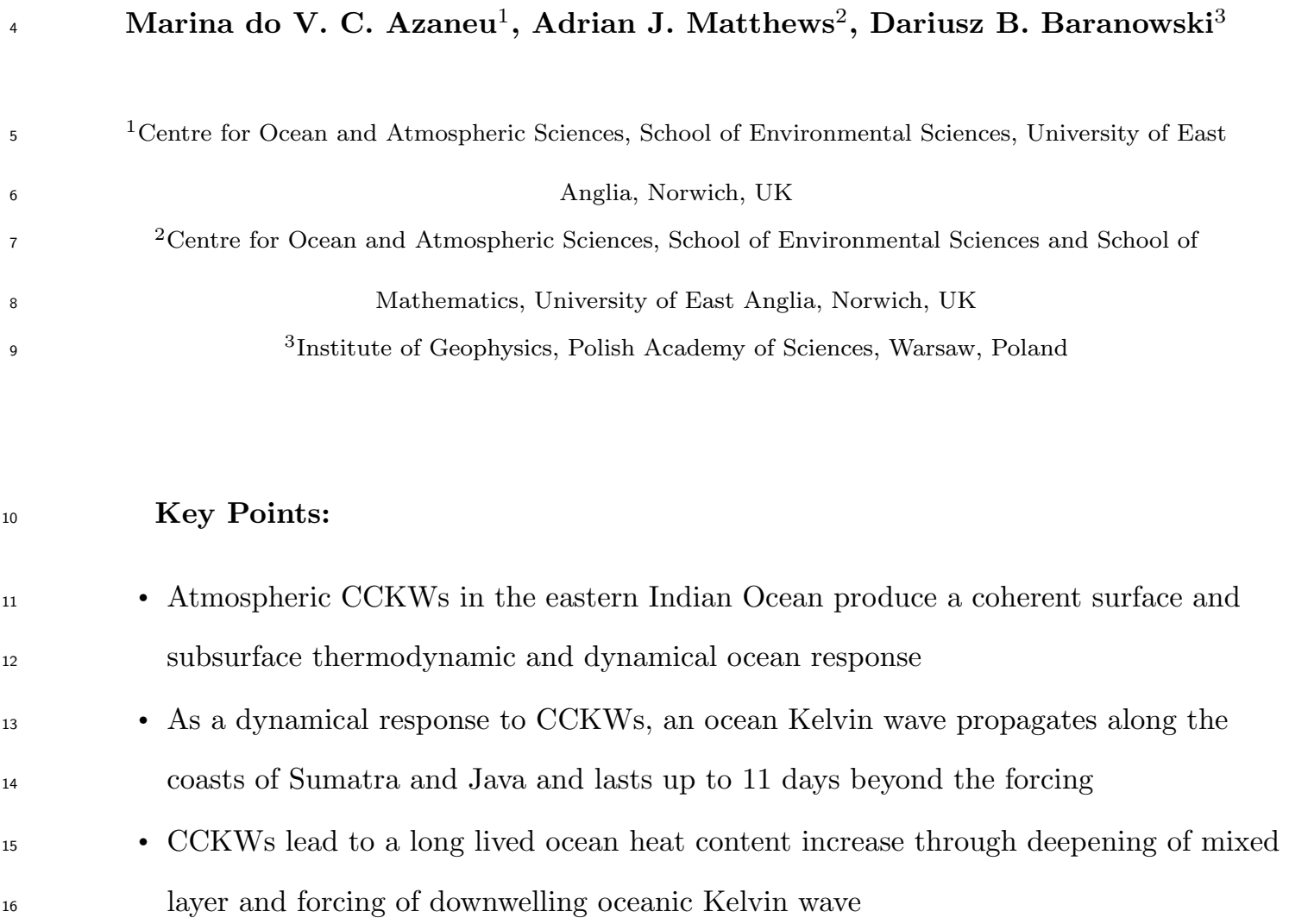

Corresponding author: Marina do V. C. Azaneu, m.azaneu@uea.ac.uk 


\section{Abstract}

Atmospheric convectively coupled equatorial Kelvin waves (CCKWs) are a major tropical weather feature strongly influenced by ocean-atmosphere interactions. However, prediction of the development and propagation of CCKWs remains a challenge for models. The physical processes involved in these interactions are assessed by investigating the oceanic response to the passage of CCKWs across the eastern Indian Ocean and Maritime Continent using the NEMO ocean model analysis with data assimilation. Threedimensional life cycles are constructed for "solitary" CCKW events. As a CCKW propagates over the eastern Indian Ocean, the immediate thermodynamic ocean response includes cooling of the ocean surface and subsurface, deepening of the mixed layer depth, and an increase in the mixed layer heat content. Additionally, a dynamical downwelling signal is observed two days after the peak in the CCKW westerly wind burst, which propagates eastward along the Equator and then follows the Sumatra and Java coasts, consistent with a downwelling oceanic Kelvin wave with an average phase speed of $2.3 \mathrm{~m} \mathrm{~s}^{-1}$. Meridional and vertical structures of zonal velocity anomalies are consistent with this framework. This dynamical feature is consistent across distinct CCKW populations, indicating the importance of CCKWs as a source of oceanic Kelvin waves in the eastern Indian Ocean. The subsurface dynamical response to the CCKWs is identifiable up to 11 days after the forcing. These ocean feedbacks on time scales longer than the CCKW life cycle help elucidate how locally driven processes can rectify onto longer time-scale processes in the coupled ocean-atmosphere system.

\section{Plain Language Summary}

We investigate the effects that the passage of a weather system (an atmospheric convectively coupled equatorial Kelvin wave, CCKW) along the Equator has in the eastern Indian Ocean. CCKWs can intensify precipitation and cause extreme weather, such as flooding, over the islands of the Maritime Continent, which include Indonesia and Malaysia. CCKWs affect the ocean and which can then feedback onto the CCKWs. A better understanding of the physical processes connecting the atmosphere and ocean during a CCKW passage is still needed to improve its prediction by models. More accurate CCKW prediction will then help to mitigate some of the consequences of the weather-related natural disasters in the region. We show that the effects of the passage of the CCKW on the ocean are relatively long-lived. For example, the increase in the amount of heat avail- 
able at the ocean surface is maintained for several days after the CCKW has passed. We also show that CCKWs are also capable of triggering dynamic processes in the ocean that can influence precipitation over the islands at a later time. These results show that CCKWs can influence oceanic and weather conditions after their passage and in remote areas, such as coastal regions.

\section{Introduction}

The equatorial Indian Ocean and its interaction with the atmosphere has an important role in influencing climate both locally and remotely (Schott et al., 2009). The region is under the influence of a wide range of modes of variability, with strong multiscale interaction between them. In particular, intraseasonal variability is strong in the equatorial Indian Ocean, which has been linked to atmospheric forcing in its central and eastern portion (e.g., Han et al., 2001; Han, 2005; Iskandar \& McPhaden, 2011). This intraseasonal oceanic variability, which tends to undergo a shift towards lower frequencies when compared to its atmospheric forcing, can then feed back onto atmospheric dynamics through ocean-atmosphere interaction, potentially influencing the evolution of longer time-scale systems, for example the Indian Ocean Dipole (Rao \& Yamagata, 2004).

On time scales of a few days, atmospheric convectively coupled Kelvin waves (CCKWs) are the primary mode of variability of eastward moving convection near the Equator (Wheeler \& Kiladis, 1999; Roundy, 2008; Kiladis et al., 2009) with phase speeds between 11 and $14 \mathrm{~ms}^{-1}$. They are accompanied by coherent dynamical atmospheric signals in wind, temperature and humidity (Wheeler et al., 2000) and are theoretically considered as equatorial Kelvin waves (Gill, 1980), modified by moist atmospheric convection.

CCKWs have a strong interaction with the underlying ocean. Enhanced surface wind speed and air-sea heat flux, besides anomalous precipitation, characterize the passage of a CCKW event, which lasts approximately 4 days at a given longitude (Baranowski et al., 2016a). The localized upper ocean response includes the temporary suppression of the diurnal cycle of SST and decrease of mean SST by $0.1-0.3^{\circ} \mathrm{C}$ as a result of airsea heat loss at the surface and subsurface turbulent mixing (Baranowski et al., 2016a; Pujiana \& McPhaden, 2018). Stratification and mixing are also modulated by surface fluxes and eastward acceleration of surface layer under intensified winds. Changes in the 
barrier layer thickness have also been reported, which may potentially limit heat transfer to subsurface layers (Pujiana \& McPhaden, 2018).

CCKWs increase precipitation along their track and locally, over the islands of the Maritime Continent, are often phase-locked with the local diurnal cycle of precipitation with a potential to amplify it (Baranowski et al., 2016b). Therefore, they contribute to extreme precipitation in the already extremely wet environment of the eastern Indian Ocean and Maritime Continent, enhancing the likelihood of flooding in islands such as Sumatra, which is home to over 50 million people (Baranowski et al., 2020). Thus, in order to help mitigate some of the consequences of weather-related natural disasters and contribute to the understanding of global climate teleconnections, a deeper understanding of the physical processes involved in the ocean-atmospheric interactions associated with CCKWs is needed.

On larger scales, the dominant mode of intraseasonal variability in the tropical Indian Ocean is the Madden-Julian Oscillation (MJO) (Zhang, 2005), which has a broadband spectral signal with an energy peak in the 40-60 day range (Madden \& Julian, 1971). The MJO also has a strong coupling with the ocean, both thermodynamically through surface fluxes (e.g. M. Flatau et al., 1997; M. K. Flatau et al., 2003; Shinoda et al., 1998; Moum et al., 2016; DeMott et al., 2015), and dynamically. For example, a "primary" MaddenJulian event can be triggered by the westward propagation of a downwelling Rossby wave from the eastern Indian Ocean (Webber et al., 2012; Rydbeck \& Jensen, 2017).

The MJO has an intrinsic multiscale structure (Birch et al., 2016; Hagos et al., 2020). CCKWs are among the several "building blocks" of the MJO multiscale structure, being embedded in its large scale convective envelope (Majda et al., 2004; Mapes et al., 2006). It is hypothesized that the propagation of the MJO envelope over the Maritime Continent is dependent on the ability of CCKWs to cross this barrier (Inness \& Slingo, 2006), An additional factor that impacts on the MJO being able to cross the Maritime Continent is its interaction with the diurnal cycle (Ling et al., 2019), which again leaves a role for CCKWs (Baranowski et al., 2016b).

Scale interactions between the MJO and CCKWs can be analysed using the framework of Meehl et al. (2001). The larger scale MJO sets the environment within which the smaller scale CCKWs develop. The CCKWs then feedback upscale to the MJO through long-lasting changes to the ocean, and atmospheric humidity. Such a rectification by CCKWs 
has already been observed through their thermodynamical impact on the ocean, with sea surface temperature (SST) changes, induced by enhanced latent heat flux from westerly wind anomalies associated with CCKWs, persisting well beyond the passage of the CCKW (Baranowski et al., 2016a).

Even though the localized effect of an atmospheric CCKW passage on the surface and subsurface ocean has been assessed, there is still uncertainty regarding the longer term effects of this atmospheric forcing in the ocean and their interaction with other modes of variability. Evaluating the upper ocean variability within the CCKW life span, Baranowski et al. (2016a) observed residual changes in some properties, suggesting that air-sea flux variability associated with the passage of a CCKW event may feedback onto longer time scale weather systems like the MJO, and thus play a key role in the tropical ocean-atmospheric system. Moreover, feedbacks between precipitation, salt-stratified oceanic barrier layers and the upper ocean diurnal cycle are likely to play important roles in the multi-scale interactions between modes of atmospheric convection.

This study aims to build on previous work by examining the three-dimensional ocean response to the passage of CCKWs on different time scales, across the eastern Indian Ocean basin and the Maritime Continent, using 10 years of an ocean analysis dataset. Section 2 describes the data and methodology used. The composite atmospheric structure of CCKWs is constructed in Section 4, to inform the thermodynamic and dynamic ocean structures associated with CCKWs in Section 5. Ocean feedbacks of CCKWs onto the atmosphere are presented in Section 6, and conclusions in Section 7.

\section{Data and methodology}

\subsection{Meteorological datasets}

Precipitation was analysed using the Tropical Rainfall Measuring Mission (TRMM) 3B42v7 precipitation product (Huffman et al., 2007), which provides 3-hourly estimates of precipitation rate on a $0.25^{\circ} \times 0.25^{\circ}$ resolution grid (approximately $28 \mathrm{~km}$ in the tropics). The analysis period for TRMM and all other variables was the 11 years from 1 January 2007 to 31 January 2017.

The TropFlux product (Kumar et al., 2012) provides daily surface downward net heat flux derived using the COARE v3.0 algorithm from a combination of bias-corrected 
ERA-Interim reanalysis and International Satellite Cloud Climatology Project (ISCCP) data. Data are available on a $1 \times 1^{\circ}$ grid over the equatorial ocean.

Components of $10 \mathrm{~m}$ wind used in this study are from the European Centre for Medium Range Weather Forecasts (ECMWF) Reanalysis Version 5 (ERA-5) reanalysis (Hersbach et al., 2020). Data are supplied on a global $0.25^{\circ} \times 0.25^{\circ}$ resolution grid. Hourly data were averaged to daily mean values.

\subsection{Ocean reanalysis dataset}

We use the NEMO ocean model analysis with data assimilation, specifically the operational Mercator global ocean analysis and forecast system (global-analysis-forecastphy-001-024 data set Madec, 2008) daily mean fields on a $1 / 12^{\circ} \times 1 / 12^{\circ}$ grid (approximately $8 \mathrm{~km}$ in the tropics), to evaluate the CCKW-associated structures of conservative temperature, absolute salinity, sea surface height, and ocean velocity between 2007 and 2017. The NEMO product has 50 vertical levels (from the surface to $5500 \mathrm{~m}$ depth) with a vertical grid spacing that increases from $1 \mathrm{~m}$ to $14.5 \mathrm{~m}$ within the upper $100 \mathrm{~m}$. Its atmospheric forcing is taken from the 3-hourly ERA-Interim data set (Dee et al., 2011). Conservative temperature $(T)$ and absolute salinity $(S)$ are derived using the TEOS-10 toolbox (McDougall \& Barker, 2011). The ability to simulate the upper ocean circulation and salinity structure was assessed for various versions of Nemo model in the Bay of Bengal, being the $1 / 12^{\circ}$ resolution the most successful (Benshila et al., 2014).

The mixed layer depth (MLD), isothermal layer depth (ILD), barrier layer thickness (BLT), heat content above the mixed layer (HC), and depth of the $20^{\circ} \mathrm{C}$ isotherm (D20) were calculated from vertical profiles of $T$ and $S$. Following Sprintall and Tomczak (1992), de Boyer Montégut et al. (2007), and Drushka et al. (2014), the ILD was defined as the depth $(D)$ at which the temperature falls to a threshold $\Delta T=0.3^{\circ} \mathrm{C}$ below a reference temperature at $5 \mathrm{~m}$ depth $T_{\text {ref }}=T(D=5)$ :

$$
\mathrm{ILD}=\left.D\right|_{T=T_{\text {ref }}-\Delta T} .
$$

The MLD was then calculated similarly, using $\Delta \sigma_{\theta}$ as the potential density change relative to the reference depth at $5 \mathrm{~m}$,

$$
\mathrm{MLD}=\left.D\right|_{\sigma_{\theta}=\sigma_{\theta}(D=5)+\Delta \sigma_{\theta}},
$$


where $\Delta \sigma_{\theta}$ is the change in potential density needed to effect a decrease in temperature of $\Delta T$, assuming salinity is held constant:

$$
\Delta \sigma_{\theta}=\sigma_{\theta}\left(T_{r e f}-\Delta T, S_{r e f}, P_{0}\right)-\sigma_{\theta}\left(T_{r e f}, S_{r e f}, P_{0}\right) .
$$

Here, $S_{\text {ref }}$ is $S$ at the reference depth of $5 \mathrm{~m}$ and $P_{0}$ is pressure at the ocean surface. The BLT is defined as

$$
\mathrm{BLT}=\mathrm{ILD}-\mathrm{MLD}
$$

The HC is calculated by integrating the amount of heat above the MLD:

$$
\mathrm{HC}=\int_{z=-\mathrm{MLD}}^{0} \rho_{w} c_{w} T d z,
$$

where $z$ is the vertical coordinate (positive upward), and $\rho_{w}$ and $c_{w}$ are the in situ density and specific heat capacity of sea water, respectively.

The calculation of the derived variables showed only a small sensitivity to the choice of the $\Delta T$ threshold. Using values of $0.3,0.4$ and $0.5^{\circ} \mathrm{C}$ for $\Delta T$ resulted in mean and standard deviations of $35.2 \pm 3.5 \mathrm{~m}$ for ILD, $24.7 \pm 3.2 \mathrm{~m}$ for MLD, and $10.5 \pm 0.3 \mathrm{~m}$ for BLT in the equatorial Indian Ocean.

\subsection{Classifying CCKW events}

Using precipitation from TRMM and the methodology of Baranowski et al. (2016a), a database of CCKW events occurring globally between 2007 and 2017 was generated. The approach tracks individual events and provides information of their longitude along the equator at 3-hourly time intervals. It utilizes space-time FFT-filtered precipitation anomalies associated with the CCKW spectrum (Kiladis et al., 2009) and defines trajectories as the continuous maxima of CCKW-filtered precipitation exceeding a threshold value (2.5 $\mathrm{mm} \mathrm{day}^{-1}$ anomaly).

The CCKW event dataset was then further subset to isolate events relevant to the area of interest. This study focuses on CCKW propagation across the Indian Ocean and the Maritime Continent. Hence, a base point longitude was set at $110^{\circ} \mathrm{E}$ in the western Maritime Continent (Fig. 1). All CCKW events considered in this study cross this base point longitude. Furthermore, to guarantee a minimum zonal extent of each CCKW event, each trajectory considered had to begin west of $90^{\circ} \mathrm{E}$ and end east of $120^{\circ} \mathrm{E}$.

These constraints led to a total of 381 such CCKW events active over the eastern Indian Ocean and Maritime Continent between 2007 and 2017. These events were fur- 
ther classified based on their instantaneous precipitation anomaly at the base point $\left(110^{\circ} \mathrm{E}\right)$ and on their average precipitation anomaly between $100-120^{\circ} \mathrm{E}$. The $N=82$ events whose precipitation anomaly was in the upper quartile (i.e., above $7.7 \mathrm{~mm} \mathrm{day}^{-1}$ ) were classified as "strong" events.

Within our CCKW subset, $52 \%$ of the strong events are preceded or followed by another CCKW event within five days. As such a large proportion of CCKW events is preceded or followed by another event within a CCKW lifetime span (approximately $4-$ 5 days; Baranowski et al., 2016a), a further classification was made to avoid interference between events and to allow an analysis of the physical response of the undisturbed ocean to the passage of a CCKW. The CCKW events that were not preceded or followed by any other event within five days, are termed "solitary" events. The results presented in this study are focused on the conditions associated with strong, solitary CCKW events $(N=36)$. There is a slight bias in the seasonal distribution of these strong, solitary CCKW events, with 22 events occurring in northern summer (April-September), and 14 in northern winter (October-March).

\subsection{CCKW composite calculation}

To create CCKW composite fields, the annual cycle was first removed from the daily time series of all variables of interest, at each grid point and level. Each time series was then filtered using a Lanczos 20-day high-pass filter with 241 weights. This filtering allows the analysis of a "pure" CCKW structure, by removing the signal of any MJO, and other atmospheric systems with a longer time scale, that the CCKWs are often embedded in. These filtered anomaly time series are then used to construct the CCKW composite fields.

A base point at $110^{\circ} \mathrm{E}$ was chosen for referencing the CCKW events. Thus, the day that each event passes through the base point at $110^{\circ} \mathrm{E}$ is defined as the lag 0 day for that event. The lagged composites are then created by averaging the anomaly fields referenced these lag 0 days. Daily composite fields from lag -10 days to +10 days were calculated.

Each individual CCKW event will have a slightly different phase speed. Each event is referenced to the day it crosses the base point at $110^{\circ} \mathrm{E}$. Hence, all the events "constructively" interfere at lag 0 to give a strong signal then. However, as the magnitude 
of the lag increases (for both positive and negative lags), the events will begin to partially destructively interfere and the composite signal may be weakened. To test for the importance of this and for the choice of base point, we composited daily lags for a range of base points (from 50 to $120^{\circ} \mathrm{E}$ ). These zero-lagged composites at different base points do not suffer from the destructive interference problem. At each longitudinal base point, we compared the lag 0 composite with its respective time-lagged-composite for the remaining longitudinal base points. It transpired that the main features were not sensitive to the choice of method (composites generated by lagging time and longitudinal base points). Hence, unless we take composites created with extreme longitudinal base points and time lags, the destructive interference at high lags is not a major problem. Based on this comparison, we identified $110^{\circ} \mathrm{E}$ as the ideal base point that allows following oceanic features propagating further east in the domain without having issues with destructive interference in the time lags of interest.

In addition to showing composite maps on horizontal surfaces, composite vertical sections are also shown. To diagnose the anticipated path of an oceanic Kelvin wave forced by the atmospheric CCKW over the Indian Ocean, three distinct vertical sections are computed, then spliced together end to end (Fig. 1a). The data along the sections were averaged over a $\pm 0.5^{\circ}$ band in latitude for section $\mathrm{A}$ and longitude for sections $\mathrm{B}$ and C. For sections B and C, which are not meridional, the data are firstly linearly interpolated onto the section with a grid that maintains the distance between points as observed at the Equator (i.e., $9.25 \mathrm{~km}$ ).

\section{Mean atmospheric and oceanic background state}

The average wind field and oceanic conditions that preceded the strong solitary CCKW events are presented in Fig. 2. These fields were computed by compositing the total fields between lags -10 and -6 days, and represent the precursor atmospheric and oceanic state that the CCKW events develop on. The slight seasonal bias to the distribution of events, as discussed in Section 2.3, is reflected in the precursor wind field, which shows a structure similar to the boreal summer monsoon (Fig. 2d).

The depth of the $20^{\circ} \mathrm{C}$ isotherm (D20; Fig. 2c) is typically used to represent the depth of the mid-thermocline in the tropical ocean, and as an indicator of the ocean dynamic response to wind forcing (Schott et al., 2009). For example, the shallower D20 ob- 
served off the coast of Java is consistent with the predominantly alongshore winds that force coastal upwelling processes in this region during northern summer. Cooler surface waters (Fig. 2a) are then associated with this upwelling.

Another climate relevant feature is the barrier layer, a consequence of temperature and salinity near-surface stratification in areas of high fresh water input. In regions of high precipitation or river discharge, for example along the Sumatran coast, the light fresh waters (Fig. 2e) cause a vertical density gradient within the relatively homogeneous temperature surface layer that will act as a "barrier" for surface heat fluxes (Godfrey \& Lindstrom, 1989; Schott et al., 2009). We observe a relatively thick barrier layer along the Sumatran coast (Fig. 2g), particularly north of the Equator, likely associated with the high precipitation rates in the region (not shown) and possibly the periodic advection of fresh plumes exiting the Sunda Strait (Potemra et al., 2016).

The temperature and salinity precursor fields are also presented along the sections A, B and C (Fig. 3a,b) to show the oceanic vertical structure. The composites clearly show the surface temperature maximum, and the upwelling system off the coast of Sumatra (section B) and Java (section C), together with the shallowing of the MLD and ILD (black and pink dashed lines; Fig. 3a). It also shows the subsurface salinity maximum (Fig. 3b), which is likely due to the advection by equatorial currents of a high salinity water mass generated in the Arabian Sea (Masson et al., 2002; Nagura \& Mcphaden, 2018; Prasad \& Ikeda, 2002), as well as the low salinity surface waters at the Sumatran coast and off the Sunda Strait (western and eastern end of section B, respectively). The distance between the MLD and the ILD indicates the thickness of the barrier layer, which increases towards the coast (Fig. 3a,b).

\section{Atmospheric structure of CCKWs}

The atmospheric structure of CCKWs is briefly described here and compared with previous studies, to provide the context and forcing fields for the oceanic subsurface structure of the CCKWs that follows in Section 5. The definition of CCKW events used here is based on eastward-propagating maxima in equatorial precipitation. Hence, as expected, lagged composite anomalies of precipitation show a coherent positive anomaly over the central Indian Ocean at lag -5 days (Fig. 1a). This propagates smoothly eastward over the eastern Indian Ocean by lag -3 days (Fig. 1b) and over the western Maritime Con- 
tinent by lag -1 day (Fig. 1c), reaching the reference longitude of $110^{\circ} \mathrm{E}$ at lag 0 , by design. By lag 1 day (Fig. 1d) the positive precipitation anomaly has reached the central Maritime Continent; it then propagates out of the domain shown in Fig. 1 at subsequent lags. The phase speed is approximately 10 degrees longitude per day $\left(13 \mathrm{~m} \mathrm{~s}^{-1}\right)$, consistent with previous observations of CCKWs (e.g., Wheeler \& Kiladis, 1999; Roundy, 2008; Baranowski et al., 2016a).

The anomalous surface wind stress vectors also show a signal consistent with the known structure of atmospheric CCKWs (Wheeler et al., 2000). An eastward-propagating patch of eastward wind stress anomalies on the equator accompanies the positive precipitation anomalies and enhanced convection there from lag -3 to -1 days (Fig. $1 \mathrm{j}, \mathrm{k}$ ).

The increase in cloudiness associated with the positive precipitation anomalies will lead to a decrease in surface shortwave radiation flux during the convectively active phase of the CCKWs. The westerly winds associated with the eastward surface wind stress anomalies will add to the mean westerly winds over the equatorial Indian Ocean, increasing surface evaporation and decreasing the (downward) surface latent heat flux into the ocean. Both these flux anomalies lead to an upward net heat flux anomaly of over $20 \mathrm{~W} \mathrm{~m}^{-2}$ into the ocean from lag -3 to -1 days (line contours showing negative NHFD anomalies in Fig. 1b,c).

In addition to the canonical eastward propagation along the equator, the CCKWs also exhibit northward and southward propagation when they reach the island of Sumatra. The Barisan mountain range runs along the western coast of Sumatra and consistently reaches altitudes of $2000 \mathrm{~m}$, well above the height of the atmospheric boundary layer, and forms a partial topographic barrier to the eastward propagation. Note that Sumatra and the mountain range run along a northwest-southeast axis, rather than a north-south axis. The convective component of the CCKWs responds to this inclined barrier, with a northward and southward extension of the convective anomalies over the eastern Indian Ocean off the coast of Sumatra at lag -1 day (Fig. 1c).

The dynamical component of the CCKWs also responds, with a stronger response to the south, as the eastward wind stress anomalies along the equator become southeastward anomalies running parallel to the Sumatran coast and mountain range (Fig. 1k). This response can be interpreted as the atmospheric equivalent to a coastal Kelvin wave (e.g. Webber et al., 2012), trapped against the topographic barrier of the Barisan moun- 
tains. An equivalent atmospheric topographically trapped Kelvin wave has previously been noted, when the atmospheric equatorial Kelvin wave component of the MJO impinges on the Andes mountain range, after traversing the Pacific Ocean (Matthews, 2000).

\section{Subsurface oceanic structure of CCKWs}

\subsection{Immediate ocean response}

\subsubsection{Thermodynamic response}

The SST over the eastern Indian Ocean and Maritime Continent generally shows a decrease during the passage of the CCKW, with negative SST anomalies appearing over the central equatorial Indian Ocean at $80^{\circ} \mathrm{E}$ at lag -3 days (Fig. $4 \mathrm{~b}$ ), then moving eastward across the domain to the eastern Indian Ocean at lag -1 day (Fig. 4c) and the western Maritime Continent by lag 1 day (Fig. 4d).

The evolution in time of the upper ocean daily temperature anomalies averaged at the Equator between $90^{\circ} \mathrm{E}-95^{\circ} \mathrm{E}$ shows the local effect of the passage of CCKW events in the SST (surface temperature in Fig. 5d). We estimate that this area experiences a decrease in temperature of $0.19^{\circ} \mathrm{C}$ between the maximum temperature anomaly observed 2 days before the CCKW passage by this longitudinal band (lag -4 day) to it's minimum anomalies the day following the event (lag -1 ; Fig. 5 d). This is consistent with previous results from Baranowski et al. (2016a). The agreement in timing and magnitude of the SST anomalies between this study and the estimate of Baranowski et al. (2016a) validates the use of NEMO data in analysing the oceanic response to CCKWs. We then use the multi-level nature of the NEMO data to extend the analysis below the surface.

The surface temperature signal extends downward in the equatorial eastern Indian Ocean (section A, lags -1 to 3 days, colour shading in Fig. 6a) through the mixed layer (MLD shown by black lines in Fig. 6a). The temperature signal becomes weaker with depth and lagged in time within the mixed layer. For example, at $25 \mathrm{~m}$ (average MLD at $90^{\circ} \mathrm{E}$ in the precursor field; Fig. 3), the minimum temperature anomaly $\left(-0.03^{\circ} \mathrm{C}\right.$; $35 \%$ of surface minimum) is observed at lag 0 , a day later than at the surface and two days after the peak CCKW precipitation anomaly at $90^{\circ} \mathrm{E}$ (Figs. 5d,h).

The surface cooling is consistent with the observed decrease in downward net heat flux (NHFD; line contours in Fig. 1a-d). This in turn is due to a combination of a de- 
crease in incoming solar radiation (inferred from the positive precipitation anomalies, and therefore increased cloudiness (colour shading in Fig. 1a-d), and strong westerly wind anomalies (Fig. 1j,k) increasing the upward latent heat flux.

Stronger winds associated with the passage of the CCKWs can also contribute to the cooling of surface waters by reducing vertical stratification through vertical mixing (Fig 5d, e.g., negative anomalies in $\mathrm{N}^{2}$ at waters above MLD coincident with positive anomalies in wind at lag -2 at Fig. Fig $5 f)$. The local change in stratification during the passage of CCKWs can be observed in the anomalies averaged over the Equator $\left(2.5^{\circ} \mathrm{N}\right.$ $2.5^{\circ} \mathrm{S}, 90^{\circ} \mathrm{E}-95^{\circ} \mathrm{E}$; Figs. 5e).

While changes in $\mathrm{N}^{2}$ (Figs. 5e) appear to be mostly aligned with temperature anomalies (Fig. 5d), salinity also contributes to it, mainly in the initial lags of enhanced precipitation (Fig. 5i). Between lags -4 to -3 , when precipitation anomalies start to increase (Fig. 5i), N2 anomalies are high (Fig. 5e) due to this input of fresh water and high surface temperatures (Fig. 5d). With the decrease in NHFD (Fig. 5a) and the increase in wind stress (Fig. 5f), temperature drops at the surface, leading to a reduction in $\mathrm{N}^{2}$ despite the continuous decrease in salinity (Lags -3 to -2 ). The wind-driven vertical mixing then acts on further reducing vertical stratification, deepening the MLD and contributing to the spreading of the negative temperature and salinity anomalies with depth (Figs. 5d,i).

Moreover, the stronger eastward wind anomalies at the Equator (Figs. 1j,k and 5f) intensify the eastward surface currents, as shown by the positive anomalies in the surface zonal currents between lags -1 and 0 (Fig. 7a). This intensification of surface currents and the momentum transference with depth (Fig. 7a) likely increases vertical shear and contributes to generation of turbulence (Moum et al., 2014; Pujiana \& McPhaden, 2018).

The role of subsurface turbulence in modulating the upper ocean temperature during CCKW events is supported by Pujiana and McPhaden (2018), who showed that, between 2011 and 2012, surface heat flux and subsurface turbulent heat fluxes had similar contributions to the surface layer cooling in this region (at $0^{\circ} \mathrm{N}, 90^{\circ} \mathrm{E}$ ). Thus, the subsurface turbulent heat fluxes can be an important contributor to maintaining the cooling of the mixed layer observed up to 8 days after the passage of CCKW events (e.g. lag +6 days in Fig. 5d). The changes in stratification observed in this study using the NEMO 
data are consistent with the in situ work of Pujiana and McPhaden (2018), and serve to spatially extend their conclusions across the Indian Ocean basin.

The heat content of the mixed layer is a key variable that impacts atmospheric convection within the CCKW and subsequent feedbacks, as it represents the reservoir of heat that is available to the atmosphere. The heat content (HC: Equation 5) is dependent on both the temperature and depth of the mixed layer. Despite the existence of negative temperature anomalies within the mixed layer, anomalies in $\mathrm{HC}$ closely follow anomalies in the MLD (Fig. 5b,d). Thus, most of the increase in $\mathrm{HC}$ observed along the Equator between lags -2 days and 0 days is likely due to deepening of MLD mostly from wind mixing (Figs. 5 and 4).

The precipitation (Fig. 5h) and wind stress (Fig. 5f) forcings for the CCKW are relatively short lived; they last 4 days, from lag -4 to 0 in the equatorial eastern Indian Ocean $\left(2.5^{\circ} \mathrm{S}-2.5^{\circ} \mathrm{N}, 90-95^{\circ} \mathrm{E}\right)$. However, the ocean response is longer lived. For example, the negative ocean temperature anomalies (Fig. 5d) last 6 days at the surface (lag -2 to 4 ) and 7 days at $20-40 \mathrm{~m}$ (lag -1 to 6 ). The increase in MLD (Fig. $5 \mathrm{~d}$ ) is also relatively long lived. This is reflected in the positive heat content anomalies (Fig. 5b), which last 6 days, from lag -1 to 5 . These results are consistent with Baranowski et al. (2016a), who hypothesized a long-lasting effect of the CCKWs based on the ocean surface response up to 5 days after the events.

\subsubsection{Dynamical response}

The ocean will also respond dynamically to the easterly wind anomalies along the equator at lag -5 days (Fig. 1i). This is evidenced by the negative anomalies in SSH and in D20 (indicating shallower depths) in this region two days after the forcing (lag -3 days; Fig. 4j), indicating oceanic upwelling. Similarly, the intensification of southeasterly winds along the Sumatran coast at lag -5 days (Fig. 1i) induces coastal upwelling two days later (lag -3 days; Fig. 4j) due to Ekman transport. The coastal upwelling signal persists at the Sumatran coast until lag 0.

Temperature anomalies in the ocean interior are consistent with the upwelling of deeper, colder waters; negative anomalies in D20 (black line in Fig. 6a) coincide with negative temperature anomalies below $70 \mathrm{~m}$ (Fig. 6a; lag -3). Because the coastal region is characterised by shallower MLD and a subsurface salinity maximum (Fig. 3b), 
this coastal upwelling is likely to be the cause of the positive salinity anomalies below the MLD (Fig. 6b; lag -3).

Coastal upwelling along the southwestern coasts of Sumatra and Java is known to be associated with prevailing southeasterly winds during the boreal summer monsoon (e.g. Wyrtki, 1962; Bray et al., 1996; Susanto et al., 2001). Even though the upwelling primarily develops between June and September (e.g., Susanto et al., 2001), intraseasonal variations in the upwelling signal are correlated with intraseasonal variations in winds (20-50 day periods) in both summer and winter monsoons along the Java coast (Horii et al., 2016). This suggests, together with our composite analysis, that the anomalies in the wind field associated with the development of CCKW events may be associated with the variability in the upwelling system at the Java coast year round, and this relation may be stronger during boreal summer when the average atmospheric conditions are more favorable for the upwelling to occur and the strong solitary events are more frequent.

The anomalies observed in D20 associated with upwelling $(\sim 1.5 \mathrm{~m}$; Fig. 4j-k and $6 \mathrm{a}$, lags -5 to -3 ) are likely relevant at the Sumatran coast. For example, Horii et al. (2016) showed that upwelling events occurring between April-August were associated with SST cooling along the Java coast, which can then impact on local atmospheric convection. Complementary to their results, we find a similar association at the coast of Sumatra (Fig. 6a, lags -5 to -3 ). This highlights the impact that CCKW events may have remotely through anomalies in the wind field and their effect on the ocean dynamics.

Similarly, westerly wind stress anomalies during the CCKW passage will also trigger an immediate oceanic dynamic response. Following the equatorial westerly wind stress intensification (lag -3 days; Fig. 1j), downwelling initiates at lag -1 day (positive D20 and sea surface height anomalies along the Equator between $82-90^{\circ}$ E; Fig. 4l) as a consequence of Ekman convergence at the Equator. This becomes a more coherent signal at later lags.

The daily anomalies averaged over the equatorial eastern Indian Ocean $\left(2.5^{\circ} \mathrm{N}-2.5^{\circ} \mathrm{S}\right.$, $90^{\circ} \mathrm{E}-95^{\circ} \mathrm{E}$; Fig. 5) show more specifically the evolution of the oceanic state in relation to the forcing. While the local westerly wind stress and precipitation anomalies peak at lag -2 days with the passage of the CCKW by $90^{\circ} \mathrm{E}$ (Figs. 5f,h), D20 and ILD anoma- 
lies in the region reach their maximum 3 days later (lag +1 day; Figs. $5 \mathrm{~g}$ and gray full line in Fig. 5d, respectively).

Dynamical changes in the ILD and variations in the MLD by mixing may have an effect on the BL thickness. A thick barrier layer can reduce the effect of surface forcing in the ocean surface temperature as it potentially inhibits downward turbulent heat flux and thus reduce cooling by entrainment (Drushka et al., 2014; Pujiana \& McPhaden, 2018). We found only small $( \pm 1 \mathrm{~m})$ local anomalies in BL thickness during the passage of strong solitary CCKW events (Fig. 5c), despite much larger variations in the MLD and ILD (black and grey lines, respectively, in Fig.5d). Anomalies in BL thickness of similar magnitude $(<2.5 \mathrm{~m})$ are found across the domain (not shown), being typically larger at the Equator. However, there is no coherent spatial pattern to these BL anomalies.

These small changes in BL thickness occur because the MLD and ILD anomalies tend to co-vary in phase (Fig. 5d). Similarly, Drushka et al. (2014) found weak $(<5 \mathrm{~m}$ peak-to-peak) anomalies in the BL in the eastern equatorial Indian Ocean during MJO events, which were also associated with co-variance between MLD and ILD. Their study argued that these small variations are likely results of noise from other subseasonal processes and due to the diversity of the MJO-related atmospheric forcing. However, using this rationale, we would expect a more coherent and stronger signal in our results, as we use a more selective approach in terms of atmospheric forcing time scales and intensity for the CCKWs. Thus, a diversity in the forcing is unlikely to be the cause of the observed low BL variations.

In contrast, Pujiana and McPhaden (2018) reported variation in the BL thickness from $10-15 \mathrm{~m}$ to $20-30 \mathrm{~m}$ during the CCKW life cycle at $90^{\circ} \mathrm{E}, 0^{\circ} \mathrm{N}$. Such large anomalies in BL thickness were argued to be a result of a strengthened salinity stratification by rainfall (Pujiana \& McPhaden, 2018). Even though the criteria we used to select CCKW events has a different principle to those used by Pujiana and McPhaden (2018), they are aimed to isolate events of consistently strong precipitation through the wave's trajectory. Thus, it was expected that we would find similarly high BL anomalies, which was not observed.

As precipitation is unlikely the cause for the discrepancy in the BL response between these studies, this must be related to differences in the strength of the wind anomalies and/or in the oceanic precursor stratification. Thus, even though the relatively thick 
BL will act to buffer the mixed layer from the deeper ocean, the small variations observed in the BL thickness (Fig. 5d) throughout the CCKW passage suggest a weak role of the BL in modulating the inhibition of downward turbulent heat flux. As a caveat, we should also consider the possibility that the discrepancy in the barrier layer thickness behavior between models and observations (e.g., Pujiana \& McPhaden, 2018) could be related to shortcomings of the reanalysis, as for example, an overly strong vertical mixing that could quickly erode the BL and be the cause of the small changes in BL thickness.

\subsection{Delayed ocean response and remote effects}

In addition to the immediate response described in Section 5.1, the passage of CCKW events will also trigger dynamical processes on longer, oceanic time scales.

We observe the eastward propagation of the downwelling anomalies that followed the westerly wind stress anomalies associated with the CCKW passage. At lag 0, the positive anomalies in D20 and SSH are mostly constrained along the equatorial band (extending from roughly between $82^{\circ} \mathrm{E}-90^{\circ} \mathrm{E}$; not shown), indicating local downwelling with change in the D20 of up to $1 \mathrm{~m}$. These anomalies travel eastward and reach the coast of Sumatra at lag +1 days, when it has developed into a coherent downwelling signal occupying a broad longitudinal range along the Equator $\left(\sim 75-99^{\circ}\right.$ E; Fig. 4l). These eastward moving positive anomalies in D20 and SSH suggest the propagation of a downwelling oceanic Kelvin wave (OKW), initially triggered by the westerly wind burst associated with the atmospheric CCKW.

The propagation along the Equator of the suggested downwelling Kelvin wave signal can also be identified by the coherent positive temperature anomalies just below the ILD (solid magenta line in Fig. 6a). These anomalies in subsurface temperature are coincident with positive D20 and SSH anomalies and intensification of subsurface zonal currents (averaged between 60-200 m; Fig. 6a). Because the region is characterised by a positive vertical temperature gradient (Fig. 3a), these positive temperature anomalies are caused by the downweling isothermals associated with the propagation of the oceanic wave and demonstrate the capacity of the atmospheric forcing in affecting the deeper ocean.

While the subsurface temperature anomalies associated with the oceanic wave become stronger and more coherent as it propagates along the Equator (lags -1 to 1; Fig. 
6a), when the wave reaches the Sumatran coast, part of the signal is lost and part of it propagates southeastward as a coastal Kelvin wave along the coast of Sumatra and Java (Figs. 6). The maximum anomalies in temperature, SSH and D20 becomes weaker as the wave propagates along the Sumatra and Java coast (lags 3 to 9; Figs. 6), suggesting energy dissipation possibly by interaction with the topography or by reflecting as Rossby waves, as observed by Webber et al. (2010) and Pujiana and McPhaden (2020). The southeasterly wind anomalies along the coast (lag 7; Fig. 1), which can shoal the thermocline via Ekman transport, could also potentially contribute to the weakening of the downwelling Kelvin wave and its signal in SSH and D20 anomalies.

Although the propagation of the oceanic wave is not easily identifiable in salinity anomalies along the section (Fig. 6b), the local variation in the salinity anomalies at the Equator (Fig. 5i) show changes in agreement with the passage of the oceanic wave (i.e., negative salinity anomalies during downwelling), with lowest anomalies at lag +1 days when MLD is deepest). These negative anomalies are expected as the background vertical salinity gradient in the region is negative, i.e., salinity increases with depth (Fig. $3 \mathrm{~b})$.

The highest anomalies of temperature and salinity are observed at lag +1 just below the ILD (Fig. 6a) and MLD (Fig. 5i), respectively. As the wave propagates eastward, these anomalies extend down to $200 \mathrm{~m}$ for temperature, while salinity anomalies are mostly restricted to the top $110 \mathrm{~m}$ (Figs. 6a-b). This difference is likely due to the background vertical gradient, which becomes relatively weak below $110 \mathrm{~m}$ for the salinity field, but remains positive for temperate up to greater depths (Fig. 3a-b).

To better assess the depth-response of the ocean to the passage of CCKWs we evaluate the vertical structure of the oceanic Kelvin wave by analysing the composite of zonal velocity anomalies in the top $180 \mathrm{~m}$ (Fig. 7a). Near the surface, zonal currents show strong positive anomalies peaking at lag 0 . The roughly uniform phase with depth observed mostly above $40 \mathrm{~m}$ coincides with the mixed layer and indicates the immediate response to wind forcing. At the MLD, there is an abrupt change of phase, with the zonal current anomalies peaking at lag 4 days immediately below the ML. Below this depth, current anomalies show a gradual vertical shift in phase, with deeper levels tending to lead shallower levels. A more pronounced phase shift is observed below $100 \mathrm{~m}$, in agreement with the structure of a Kelvin wave forced at the surface which, as suggested by linear wave the- 
ory, would propagate phase upward and energy downward into the ocean interior (McCreary, Jr., 1984; Iskandar \& McPhaden, 2011).

From the time the oceanic wave reaches the Sumatran coast (lag +1 days; three days after the passage of CCKWs by $90^{\circ} \mathrm{E}$, Figs. $4 \mathrm{l}$ and 6a), it takes on average 3 days for it to travel along the coast and reach the Sunda Strait (lag +4 days, Fig. $4 \mathrm{~m})$, through which part of the signal seems to propagate within the Java Sea and Karimata Strait (lag +5 days, positive anomalies in SSH, Fig. 4n). It takes on average 11 days after the passage of CCKWs by $90^{\circ} \mathrm{E}$ for the signal of the oceanic Kelvin wave present in the $\mathrm{SSH}$, D20 subsurface temperature and zonal current anomalies to leave the Sumatran coast and be restricted to the coast of Java (lag +9 days, Fig. 4p). This roughly corresponds to 9 days travel since the Kelvin wave signal was identified at $90^{\circ} \mathrm{E}$.

To evaluate the wave horizontal speeds observed in the anomalies, we compare the meridional structure of the zonal velocity anomalies (averaged between $100-200 \mathrm{~m}$ at $90^{\circ} \mathrm{E}$; Fig. 7b) with Kelvin wave theory. For this analysis we used a 90-day high-pass filter to take into consideration the longer time scales associated with oceanic response, observed for example by a "red shift" in the spectrum of the ocean response to intraseasonal atmospheric forcing (e.g., Han, 2005; Iskandar \& McPhaden, 2011; Nagura \& McPhaden, 2012). In this analysis we exceptionally constructed the velocity anomaly composites using a base point at $\left(90^{\circ} \mathrm{E}\right)$. As the aim of this analysis is to investigate the initiation of the dynamic response, the choice of a base point closer to the region where the oceanic waves are excited intends to reduce signal interference due to different wave speeds of propagation. The magnitude of the depth-averaged zonal velocity anomalies at lag +3 days (in this case, 5 days after the passage of the CCKW event) approximates to a Gaussian distribution in latitude within $4^{\circ} \mathrm{S}-4^{\circ} \mathrm{N}$ (red circles in Fig. $7 \mathrm{~b}$ ), in agreement with the meridional structure of a Kelvin wave.

The depth-averaged composite zonal velocity $u^{\prime}(y)$ was least-squares fitted to the theoretical Kelvin wave solution on an equatorial $\beta$ plane (Fig. 7b) :

$$
u^{\prime}(y)=u_{0} e^{-\beta y^{2} / 2 c},
$$

where $\beta=2.3 \times 10^{-11} \mathrm{~m}^{-1} \mathrm{~s}^{-1}$ is the specified northward gradient of planetary vorticity at the Equator, $y$ is distance (in $\mathrm{m}$ ) northward from the equator, and the free parameters are $u_{0}$ amplitude of the wave and $c$ (the wave phase speed). The best fit values are $u_{0}=0.034 \mathrm{~m} \mathrm{~s}^{-1}$ and $c=0.48 \mathrm{~m} \mathrm{~s}^{-1}$ (blue line in Fig. $7 \mathrm{~b}$ ), which gives an equa- 
torial trapping scale $L=\sqrt{2 c / \beta}$ of $290 \mathrm{~km}$. The estimated phase speed is close to the Kelvin wave theoretical phase speed of the fifth vertical baroclinic mode, which is approximately $0.6 \mathrm{~m} \mathrm{~s}^{-1}$ (Moore \& McCreary, 1990). The vertical structure of the fifth mode has crossing points (zero anomaly) at approximately 50 and $150 \mathrm{~m}$ depths (Webber et al., 2014). This matches the observed structure of the ocean response to the CCKWs here, as there are crossing points in the zonal current profile at lag 0 at 50 and $130 \mathrm{~m}$ (Fig. 7a).

The theoretical phase velocity extracted from the data does not match perfectly to the theoretical phase velocity of a single projected mode. Such match should not be expected as, unless the ocean signal is isolated to depict a specific oscillation, it includes the main excited mode (in this case, the fifth) and the contribution from other multiple vertical modes. This is because the CCKW wind forcing will project onto a number of modes, and processes such as constructive interference between wind-forced internal waves and Rossby wave reflection at the eastern boundary can mix energy between modes (Nagura \& McPhaden, 2012).

Several studies have highlighted the relationship between the intraseasonal wind forcing (e.g. MJO) and an oceanic response dominated mainly by the first two baroclinic modes (e.g. Han, 2005; Iskandar et al., 2005; Halkides et al., 2015; Pujiana \& McPhaden, 2020). In contrast, we show that the oceanic response to CCKWs is dominated primarily by a higher (fifth) baroclinic mode when considering oscillations with periods shorter than 90 days. This difference in the main mode excited by the different forcings may be one of the factors contributing to the CCKW related anomalies in SSH $(0.3-0.6 \mathrm{~cm}$; Fig. 4i-p) being considerably smaller than anomalies associated with the MJO (e.g. 15- $20 \mathrm{~cm}$; Matthews et al., 2010), as its primarily the first modes that make significant contributions to the sea level signal (Cane, 1984).

Based on common features identified in Hovmöller diagrams of composite anomalies of zonal velocity (averaged between 100-200 m), D20 and heat content of the mixed layer (Fig. 8), the observed signal speeds along the Equator and coasts of Sumatra and Java are calculated. Black lines in Fig. $8 \mathrm{a}$ are positioned at the center of positive velocity anomalies; the different slopes indicate that the signal speed is not uniform along its pathway. As the oceanic signal propagates along the Equator (section A; lags -2 to 3), there is still a component of the atmospheric forcing moving eastward at $\sim 10 \mathrm{~m} \mathrm{~s}^{-1}$ (with 
speed much higher than any oceanic mode phase speed) and forcing the ocean, leading to a forced oceanic signal that propagates at relatively high speed (on average $3.2 \mathrm{~m} \mathrm{~s}^{-1}$ ). On reaching the coast, the signal loses energy and stalls, decreasing its average speed to $1.9 \mathrm{~m} \mathrm{~s}^{-1}$ and $2.0 \mathrm{~m} \mathrm{~s}^{-1}$ while propagating along the coast of Sumatra and Java, respectively. The average speed along the entire pathway is $2.3 \mathrm{~m} \mathrm{~s}^{-1}$.

The observed average speeds are higher than the estimated theoretical wave speed at the Equator. The difference between these two estimates is expected, as the latter addresses the generation of the oceanic signal, being an estimate of the main mode excited instantaneously by the forcing with the least possible interference. However, the former represents the velocity with which the signal effectively propagates through the domain, which will result from a combination of the main excited modes, the selective dissipation of the modes, the constructive interference between propagating signals in the ocean, and the presence of the time-dependent forcing during the propagation of the oceanic signal.

The variability of OKW phase speeds along their trajectories, and between Kelvin wave events, was analysed by Drushka et al. (2010), who estimated phase speeds in the range $1.6-6.1 \mathrm{~m} \mathrm{~s}^{-1}$ (average of $2.6 \pm 1 \mathrm{~m} \mathrm{~s}^{-1}$ ) for waves crossing the equatorial Indian Ocean and along the coast of Sumatra, using 30-90-day filtered altimetric sea level anomalies. This is further evidence of a spread of OKW speeds along their trajectories, and is in agreement with the range of values estimated in this study. Using in situ data and satellite altimetry, Iskandar et al. (2005) estimated phase speeds of OKWs associated with intraseasonal atmospheric forcing ranging between $1.5-2.9 \mathrm{~m} \mathrm{~s}^{-1}$ along the coast of Sumatra and Java. Further southeast, Syamsudin et al. (2004) estimated phase speeds between $1-3 \mathrm{~m} \mathrm{~s}^{-1}$ for OKWs entering Lombok Strait $\left(8^{\circ} 46^{\prime} \mathrm{S} ; 115^{\circ} 44^{\prime} \mathrm{E}\right)$. These estimates are all consistent with our findings for the OKW speeds along the coast of Sumatra $\left(1.9 \mathrm{~m} \mathrm{~s}^{-1}\right)$ and Java $\left(2.0 \mathrm{~m} \mathrm{~s}^{-1}\right)$, associated with CCKW forcing.

In contrast to previous studies which actively selected or filtered general Kelvin waves in the ocean (e.g. Syamsudin et al., 2004; Drushka et al., 2010; Iskandar et al., 2005; Pujiana \& McPhaden, 2020), this study focuses on interpreting a wave signature that arises consistently in the ocean as a response to specific atmospheric forcing events, i.e., strong solitary CCKWs. Consequently, differences in the estimated wave properties, such as the dominant baroclinic mode and the wave speed, may be expected. However, the major 
features identified in the vertical and meridional structures of the oceanic anomalies are consistent with previous studies. Moreover, the wave-like signal is not sensitive to the choice of a base point, showing consistency in the generation of this oceanic feature. These results thus indicate that the passage of CCKWs is an important source for generation of oceanic Kelvin waves in the eastern Indian ocean.

\section{Oceanic feedback}

Deepening of the thermocline associated with propagation of oceanic Rossby waves, and subsequent increase in SST due to reduced entrainment of subsurface cold waters, leads to changes in surface heat fluxes that can subsequently feed back into MJO development (Webber et al., 2012). In a similar way, the deepening of the MLD and consequent increase in $\mathrm{HC}$ observed with the passage of CCKW events (Fig. 4s-v) can feedback onto the atmosphere by modulating atmospheric boundary layer temperature (Baranowski et al., 2016a), and potentially contribute to the development of following CCKW events or even processes with time scales different from the initial forcing.

To evaluate the net effect of the passage of strong solitary CCKW events through the study area, the increase in heat content within the ML (in the box $8^{\circ} \mathrm{S}-4^{\circ} \mathrm{N}, 75-100^{\circ} \mathrm{E}$ ), from before the passage of the CCKW event (lags -10 to -6 days), to after the passage (lags 0 to 4 days) is estimated to be $1.52 \times 10^{8} \mathrm{~J} \mathrm{~m}^{-2}$ (Fig. 5j). These domain-averaged $\mathrm{HC}$ anomalies (Fig. 5j) due to solitary strong events remain positive for 6 days, longer than the CCKW time-span, similar to that observed for the local anomalies at the Equator (Fig. 5b).

The domain-averaged increase in the $\mathrm{HC}$ includes both the immediate increase in HC associated with deepening of MLD by wind mixing during the passage of the CCKW (Fig. 5b), and the remote effects of the CCKW on the HC by the propagation of the oceanic wave Figs. $8 \mathrm{~b}$ and $4 \mathrm{u}, \mathrm{v}$ ). For example, at lag +5 days (Fig. $4 \mathrm{v}$ ), the remote oceanic response to the atmospheric forcing, generated initially in the equatorial band, can be identified by the increase in HC related to a deeper MLD off the coast of Sumatra. This increase in $\mathrm{HC}$ can then interact with atmospheric processes such as the diurnal precipitation cycle, and can even influence local flooding (Baranowski et al., 2016b, 2020). Thus, the oceanic feedback from the passage of CCKWs can occur away from the forcing region and influence processes with time scales different from the initial forcing. 


\section{Conclusions}

This study uses a variety of atmospheric datasets and the oceanic NEMO analysis to build a three-dimensional view of the oceanic response to the passage of CCKWs through the eastern equatorial Indian Ocean between 2007 and 2017. The analysis is focused on the robust oceanic response to isolated ("solitary") strong forcing events, aiming at a better understanding of the physical processes without interference between CCKW events.

Using a statistical approach based on daily composite anomalies, our results show an immediate local thermodynamic and dynamic oceanic response to the passage of the CCKW through the eastern Indian ocean. As downward net heat flux decreases, and eastward winds and currents intensify, vertical shear is likely enhanced by momentum transference from the atmosphere to the ocean, leading to surface and upper ocean cooling, and a consequent decrease in vertical stratification. As the mixed layer deepens, there is an increase of the mixed layer heat content. These local effects in the ocean surface and interior are shown to last for longer than the local atmospheric forcing. For example, the increase in the mixed layer heat content lasts for six days after the passage of the CCKW, which may then feed back into the atmospheric boundary layer, supporting suggestions from previous studies that CCKWs have a rectifying effect.

Anomalies observed in the wind field related to strong CCKW events are shown to be associated with variability in the upwelling system along the coast of Sumatra and Java, as a dynamical response to the atmospheric forcing. These coastal upwelling events could have a local impact on atmospheric convection by modulating SST (Horii et al., 2016) and also on biological productivity off the Sumatran coast by modifying near-surface nutrient availability Iskandar et al. (2009).

The passage of CCKWs also triggers a consistent oceanic dynamic response on longer time scales. The initial downwelling observed at the Equator associated with the atmospheric forcing develops into a signal identified as a downwelling oceanic Kelvin wave. The propagation of this wave signal is identified in the ocean surface and interior up to 11 days after the passage of the CCKW. The structure of the oceanic signal is consistent with wave theory and shows that, in contrast to the typical response to intraseasonal wind forcing (e.g., Iskandar et al., 2005; Halkides et al., 2015; Pujiana \& McPhaden, 2020), CCKWs primarily excite higher oceanic Kelvin wave baroclinic modes. The ob- 
served oceanic wave signal propagates along the eastern equatorial Indian ocean to the coast of Java carrying energy into the ocean interior, with an average horizontal speed $\left(2.3 \mathrm{~m} \mathrm{~s}^{-1}\right)$ consistent with observational studies. These results indicate that CCKWs are an important source for generation of Kelvin waves in the eastern Indian Ocean and highlight their impact on oceanic conditions away from their main equatorial pathway.

Among the CCKW remote effects is the increase in HC due to MLD deepening observed along the Sumatran coast up to 7 days after the peak in the forcing at the Equator. Hence, the oceanic feedback to the forcing may occur in remote areas, and possibly influence processes of different time scales, such as daily precipitation cycles, or intensify the conditions for flooding in the nearby populated areas.

Within the study period, the number of solitary CCKW events, on which we focus our study, provide a clear statistical representation of the processes associated with this atmospheric weather system. However, they do not represent the majority of events; CCKW events are frequently followed by another CCKW event within their life cycle. In this scenario, the existence of a second peak in the atmospheric forcing would produce an effect in the ocean that could interact with the first signal, and potentially lead to higher amplitude and longer lasting anomalies. Further investigation is required to understand which factors are most important in defining the development of such sequential CCKWs, and how these feedback onto the system. Finally, the understanding of the processes involved in the response to isolated forcing is important not only to feedback into forecast models, but also to further comprehend the interaction of these responses with forcing of similar or multi-time scales.

\section{Acknowledgments}

This work was part of the Equatorial Line Observations project, funded by the UK Natural Environment Research Council (NERC; grant NE/R012431/1) and the US National Science Foundation (NSF; grant 1724741), and the TerraMaris project (grant NE/R016704/1). D.B.B. has been supported by the Foundation for Polish Science (The Multi-scale interactions over the Maritime Continent and their role in weather extremes over Central and Eastern Europe project is carried out within the Operational Programme Smart Growth 2014-2020, Measure 4.4: Increasing the human potential in R\&D sector, HOMING programme of the Foundation for Polish Science co-financed by the European Union under the European Regional Development Fund). The TRMM 3B42 data were downloaded 
from NASA/Goddard Space Flight Center (https://disc.gsfc.nasa.gov/datasets/ TRMM_3B42_Daily_7/summary), ERA-5 data from the Copernicus data centre (https:// cds.climate. copernicus. eu/cdsapp\#!/dataset/reanalysis-era5-pressure-levels ?tab $=$ form), and Tropflux data from the Indian National Centre for Ocean Information Services (https://incois.gov.in/tropflux/data_access.jsp) and Nemo ocean model analysis with data from Copernicus data centre (https://resources.marine.copernicus .eu/?option=com_csw\&view=details\&product_id=GLOBAL_ANALYSIS_FORECAST_PHY_001 -024). The research presented in this paper was partially carried out on the High Performance Computing Cluster supported by the Research Computing Service at the University of East Anglia. 


\section{References}

Baranowski, D. B., Flatau, M. K., Flatau, P. J., Karnawati, D., Barabasz, K., Labuz, M., .. Marzuki (2020). Social-media and newspaper reports reveal large-scale meteorological drivers of floods on Sumatra. Nature Communications, 11(1), 1-10. Retrieved from http://dx.doi.org/10.1038/ s41467-020-16171-2 doi: 10.1038/s41467-020-16171-2

Baranowski, D. B., Flatau, M. K., Flatau, P. J., \& Matthews, A. J.

$(2016 \mathrm{a}$ mar). Impact of atmospheric convectively coupled equatorial Kelvin waves on upper ocean variability. Journal of Geophysical Research, 121(5), 20452059. Retrieved from http://doi.wiley.com/10.1002/2015JD024150 doi: 10.1002/2015JD024150

Baranowski, D. B., Flatau, M. K., Flatau, P. J., \& Matthews, A. J. (2016b). Phase locking between atmospheric convectively coupled equatorial Kelvin waves and the diurnal cycle of precipitation over the Maritime Continent. Geophysical Research Letters, 43(15), 8269-8276. doi: 10.1002/2016GL069602

Benshila, R., Durand, F., Masson, S., Bourdallé-Badie, R., de Boyer Montégut, C., Papa, F., \& Madec, G. (2014). The upper Bay of Bengal salinity structure in a high-resolution model. Ocean Modelling, 74, 36-52. Retrieved from http://dx.doi.org/10.1016/j.ocemod.2013.12.001 doi: 10.1016/j.ocemod.2013.12.001

Birch, C. E., Webster, S., Peatman, S. C., Parker, D. J., Matthews, A. J., Li, Y., \& Hassim, M. E. (2016). Scale interactions between the MJO and the western Maritime Continent. Journal of Climate, 29(7), 2471-2492. doi: 10.1175/JCLI-D-15-0557.1

Bray, N. A., Hautala, S., Chong, J., \& Pariwono, J. (1996, may). Large-scale sea level, thermocline, and wind variations in the Indonesian throughflow region. Journal of Geophysical Research: Oceans, 101(C5), 12239-12254. Retrieved from http://doi.wiley.com/10.1029/96JC00080 doi: 10.1029/96JC00080

Cane, M. A. (1984). Modeling Sea Level During El Niño. Journal of Physical Oceanography, 14(12), 1864-1874. doi: 10.1175/1520-0485(1984)014〈1864: mslden $>2.0 . c 0 ; 2$

de Boyer Montégut, C., Mignot, J., Lazar, A., \& Cravatte, S. $\quad$ (2007). Control of salinity on the mixed layer depth in the world ocean: 1. General de- 
scription. Journal of Geophysical Research: Oceans, 112(6), 1-12. doi: 10.1029/2006JC003953

Dee, D. P., Uppala, S. M., Simmons, A. J., Berrisford, P., Poli, P., Kobayashi, S., ... Vitart, F. (2011). The ERA-Interim reanalysis: Configuration and performance of the data assimilation system. Quarterly Journal of the Royal Meteorological Society, 137(656), 553-597. doi: 10.1002/qj.828

DeMott, C. A., Klingaman, N. P., \& Woolnough, S. J. (2015). Atmosphere-ocean coupled processes in the Madden-Julian oscillation. Reviews of Geophysics, 53(4), 1099-1154. doi: 10.1002/2014RG000478

Drushka, K., Sprintall, J., \& Gille, S. T. (2014, feb). Subseasonal variations in salinity and barrier-layer thickness in the eastern equatorial Indian Ocean. Journal of Geophysical Research: Oceans, 119(2), 805-823. Retrieved from http://doi .wiley.com/10.1002/2013JC009422 doi: 10.1002/2013JC009422

Drushka, K., Sprintall, J., Gille, S. T., \& Brodjonegoro, I. (2010). Vertical structure of Kelvin waves in the Indonesian throughflow exit passages. Journal of Physical Oceanography, 40(9), 1965-1987. doi: 10.1175/2010JPO4380.1

Flatau, M., Flatau, P. J., Phoebus, P., \& Niiler, P. P. ～(1997). The feedback between equatorial convection and local radiative and evaporative processes: The implications for intraseasonal oscillations. Journal of the Atmospheric Sciences, 54 (19), 2373-2386. doi: 10.1175/1520-0469(1997)054<2373: TFBECA $>2.0 . \mathrm{CO} ; 2$

Flatau, M. K., Flatau, P. J., Schmidt, J., \& Kiladis, G. N. (2003). Delayed onset of the 2002 Indian monsoon. Geophysical Research Letters, 30(14), 28-31. doi: 10 $.1029 / 2003$ GL017434

Gill, A. (1980). Some simple solutions for heat-induced tropical circulation. Quarterly Journal of the Royal Meteorological Society, 106(449), 447-462. doi: 10 $.1256 /$ smsqj. 44904

Godfrey, J. S., \& Lindstrom, E. J. (1989). The heat budget of the equatorial western Pacific surface mixed layer. Journal of Geophysical Research, 94(C6), 8007. doi: $10.1029 /$ jc094ic06p08007

Hagos, S., Foltz, G. R., Zhang, C., Thompson, E., Seo, H., Chen, S., ... Protat, A. (2020). Atmospheric convection and air-sea interactions over the tropical oceans: Scientific progress, challenges, and opportunities.

Bul- 

10.1175/BAMS-D-19-0261.1

Halkides, D. J., Waliser, D. E., Lee, T., Menemenlis, D., \& Guan, B. (2015). Quantifying the processes controlling intraseasonal mixed-layer temperature variability in the tropical Indian Ocean. Journal of Geophysical Research: Oceans, 120(2), 692-715. doi: 10.1002/2014JC010139

Han, W. (2005). Origins and Dynamics of the 90-Day and 3060-Day Variations in the Equatorial Indian Ocean. Journal of Physical Oceanography, 35(5), 708-728. Retrieved from http://journals.ametsoc.org/doi/abs/10.1175/ JP02725. 1 doi: $10.1175 / J P O 2725.1$

Han, W., Lawrence, D. M., \& Webster, P. J. (2001). Dynamical response of equatorial Indian Ocean to intraseasonal winds: Zonal flow. Geophysical Research Letters, 28(22), 4215-4218. doi: 10.1029/2001GL013701

Hersbach, H., Bell, B., Berrisford, P., Hirahara, S., Horányi, A., Muñoz-Sabater, J., ... Thépaut, J. N. (2020). The ERA5 global reanalysis. Quarterly Journal of the Royal Meteorological Society, 146(730), 1999-2049. doi: 10.1002/qj.3803

Horii, T., Ueki, I., Syamsudin, F., Sofian, I., \& Ando, K. (2016, apr). Intraseasonal coastal upwelling signal along the southern coast of Java observed using Indonesian tidal station data. Journal of Geophysical Research: Oceans, 121(4), 2690-2708. Retrieved from https://onlinelibrary.wiley.com/doi/abs/ 10.1002/2015JC010886 doi: 10.1002/2015JC010886

Huffman, G. J., Adler, R. F., Bolvin, D. T., Gu, G., Nelkin, E. J., Bowman, K. P., .. Wolff, D. B. (2007). The TRMM Multisatellite Precipitation Analysis (TMPA): Quasi-global, multiyear, combined-sensor precipitation estimates at fine scales. Journal of Hydrometeorology, 8(1), 38-55. doi: $10.1175 / J H M 560.1$

Inness, P. M., \& Slingo, J. M. (2006). The interaction of the Madden-Julian Oscillation with the Maritime Continent in a GCM. Quarterly Journal of the Royal Meteorological Society, 132(618 A), 1645-1667. doi: 10.1256/qj.05.102

Iskandar, I., Mardiansyah, W., Masumoto, Y., \& Yamagata, T. (2005). Intraseasonal Kelvin waves along the southern coast of Sumatra and Java. Journal of Geophysical Research C: Oceans, 110(4), C04013-undefined. doi: 10.1029/2004JC002508 
Iskandar, I., \& McPhaden, M. J. (2011). Dynamics of wind-forced intraseasonal zonal current variations in the equatorial Indian Ocean. Journal of Geophysical Research: Oceans, 116(6), C06019-undefined. doi: 10.1029/2010JC006864

Iskandar, I., Rao, S. A., \& Tozuka, T. (2009). Chlorophyll-a bloom along the southern coasts of Java and Sumatra during 2006. International Journal of Remote Sensing, 30(3), 663-671. doi: 10.1080/01431160802372309

Kiladis, G. N., Wheeler, M. C., Haertel, P. T., Straub, K. H., \& Roundy, P. E. (2009, apr). Convectively coupled equatorial waves. Reviews of Geophysics, 47(2), RG2003. Retrieved from http://doi.wiley.com/10.1029/ 2008RG000266 doi: 10.1029/2008RG000266

Kumar, B. P., Vialard, J., Lengaigne, M., Murty, V. S., \& McPhaden, M. J. (2012). TropFlux: Air-sea fluxes for the global tropical oceans-description and evaluation. Climate Dynamics, 38(7-8), 1521-1543. doi: 10.1007/s00382-011-1115-0

Ling, J., Zhang, C., Joyce, R., Xie, P., \& Chen, G. (2019, mar). Possible Role of the Diurnal Cycle in Land Convection in the Barrier Effect on the MJO by the Maritime Continent. Geophysical Research Letters, 46(5), 3001-3011. Retrieved from https://onlinelibrary.wiley.com/doi/abs/10.1029/ 2019GL081962 doi: 10.1029/2019GL081962

Madden, R. A., \& Julian, P. R. (1971, jul). Detection of a 4050 Day Oscillation in the Zonal Wind in the Tropical Pacific. Journal of the Atmospheric Sciences, 28(5), 702-708. Retrieved from http://journals.ametsoc.org/doi/abs/ 10.1175/1520-0469\{\\%\}281971\{\\%\}29028\{\\%\}3C0702\{\\%\}3ADOADOI $\{\backslash \%\} 3 E 2$ .0.CO\{\\%\}3B2 doi: 10.1175/1520-0469(1971)028<0702:DOADOI $\rangle 2.0 . \mathrm{CO} ; 2$

Madec, G. (2008). Nemo ocean engine. Note du $P \backslash{ }^{\wedge}$ ole de $\bmod \{\backslash$ 'e $\}$ lisation, Institut Pierre-Simon Laplace (IPSL), 27, 219.

Majda, A. J., Khouider, B., Kiladis, G. N., Straub, K. H., \& Shefter, M. G. (2004). A model for convectively coupled tropical waves: Nonlinearity, rotation, and comparison with observations. Journal of the Atmospheric Sciences, 61(17), 2188-2205. doi: 10.1175/1520-0469(2004)061〈2188:AMFCCT)2.0.CO;2

Mapes, B., Tulich, S., Lin, J., \& Zuidema, P. (2006). The mesoscale convection life cycle: Building block or prototype for large-scale tropical waves? Dynamics of Atmospheres and Oceans, 42(1-4), 3-29. doi: 10.1016/j.dynatmoce.2006.03 .003 
Masson, S., Delecluse, P., Boulanger, J.-P., \& Menkes, C. $\quad$ (2002, dec). A model study of the seasonal variability and formation mechanisms of the barrier layer in the eastern equatorial Indian Ocean.

Journal of Geophysical Research: Oceans, 107(C12), SRF 18-1-SRF 18-20. Retrieved from http:// doi.wiley.com/10.1029/2001JC000832 doi: 10.1029/2001JC000832

Matthews, A. J. (2000). Propagation mechanisms for the Madden-Julian Oscillation. Quarterly Journal of the Royal Meteorological Society, 126(569), 26372651. doi: 10.1256/smsqj.56901

Matthews, A. J., Singhruck, P., \& Heywood, K. J. (2010). Ocean temperature and salinity components of the Madden-Julian oscillation observed by Argo floats. Climate Dynamics, 35(7), 1149-1168. doi: 10.1007/s00382-009-0631-7

McCreary, Jr., J. P. (1984, may). Equatorial beams. Journal of Marine Research, 42(2), 395-430. Retrieved from http://openurl.ingenta.com/content/ xref?genre=article $\{\backslash \&\}$ issn $=0022-2402\{\backslash \&\}$ volume $=42\{\backslash \&\}$ issue $=$ $2\{\backslash \&\}$ spage $=395$ doi: $10.1357 / 002224084788502792$

McDougall, T. J., \& Barker, P. M. (2011). Getting started with TEO-10 and the Gibbs Seawarer Oceanographic Toolbox. SCOR/IAPSO WG127. Retrieved from http: //www . teos-10.org/

Meehl, M., Lukas, R., Kiladis, G. N., Weickmann, K. M., Matthews, A. J., \& Wheeler, M. (2001). A conceptual framework for time and space scale interactions in the climate system. Climate Dynamics, $17(10), 753-775 . \quad$ doi: $10.1007 / \mathrm{s} 003820000143$

Moore, D. W., \& McCreary, J. P. (1990). Excitation of intermediate-frequency equatorial waves at a western ocean boundary: With application to observations from the Indian Ocean. Journal of Geophysical Research, 95(C4), 5219. Retrieved from http://doi.wiley.com/10.1029/JC095iC04p05219 doi: 10.1029/JC095iC04p05219

Moum, J. N., De Szoeke, S. P., Smyth, W. D., Edson, J. B., DeWitt, H. L., Moulin, A. J., ... Fairall, C. W. (2014). Air-sea interactions from westerly wind bursts during the november 2011 MJO in the Indian Ocean. Bulletin of the American Meteorological Society, 95(8), 1185-1199. doi: 10.1175/BAMS-D-12-00225.1

Moum, J. N., Pujiana, K., Lien, R. C., \& Smyth, W. D. (2016). Ocean feedback to pulses of the Madden-Julian Oscillation in the equatorial Indian Ocean. Nature 
Communications, 7(May), 1-7. Retrieved from http://dx.doi.org/10.1038/ ncomms13203 doi: 10.1038/ncomms13203

Nagura, M., \& McPhaden, M. J. (2012). The dynamics of wind-driven intraseasonal variability in the equatorial Indian Ocean. Journal of Geophysical Research: Oceans, 117(2), 1-16. doi: 10.1029/2011JC007405

Nagura, M., \& Mcphaden, M. J. (2018). The shallow overturning circulation in the Indian Ocean. Journal of Physical Oceanography, 48(2), 413-434. doi: 10 $.1175 /$ jpo-d-17-0127.1

Potemra, J. T., Hacker, P. W., Melnichenko, O., \& Maximenko, N.

(2016, jul) Satellite estimate of freshwater exchange between the Indonesian Seas and the Indian Ocean via the Sunda Strait. Journal of Geophysical Research: Oceans, 121(7), 5098-5111. Retrieved from http://doi.wiley.com/10.1002/ 2015JC011618https://onlinelibrary.wiley.com/doi/abs/10.1002/ 2015JC011618 doi: 10.1002/2015JC011618

Prasad, T. G., \& Ikeda, M. (2002). The wintertime water mass formation in the Northern Arabian Sea: A model study. Journal of Physical Oceanography, 32(3), 1028-1040. doi: 10.1175/1520-0485(2002)032〈1028:TWWMFI $\rangle 2.0 . C O$; 2

Pujiana, K., \& McPhaden, M. J. (2018). Ocean Surface Layer Response to Convectively Coupled Kelvin Waves in the Eastern Equatorial Indian Ocean. Journal of Geophysical Research: Oceans, 123(8), 5727-5741. doi: 10.1029/2018JC013858

Pujiana, K., \& McPhaden, M. J. (2020). Intraseasonal Kelvin Waves in the Equatorial Indian Ocean and their Propagation into the Indonesian Seas. Journal of Geophysical Research: Oceans, 125(5), 1-18. doi: 10.1029/2019jc015839

Rao, S. A., \& Yamagata, T. (2004). Abrupt termination of Indian Ocean dipole events in response to intraseasonal disturbances. Geophysical Research Letters, 31 (19), 1-4. doi: 10.1029/2004GL020842

Roundy, P. E. (2008). Analysis of convectively coupled Kelvin waves in the Indian ocean MJO. Journal of the Atmospheric Sciences, 65(4), 1342-1359. doi: 10 $.1175 / 2007 J A S 2345.1$

Rydbeck, A. V., \& Jensen, T. G. (2017). Oceanic impetus for convective onset of the Madden-Julian oscillation in the western Indian ocean. Journal of Climate, 

30(11), 4299-4316. doi: 10.1175/JCLI-D-16-0595.1

Schott, F. A., Xie, S.-P., \& McCreary Jr, J. P. (2009). Indian Ocean Circulation and Climate Variability. Reviews of Geophysics, 47(2007), 1-46. Retrieved from http://www.agu.org/pubs/crossref/2009/2007RG000245.shtml doi: 10.1029/2007RG000245.1

Shinoda, T., Hendon, H. H., \& Glick, J. (1998). Intraseasonal Variability of Surface Fluxes and Sea Surface Temperature in the Tropical Western Pacific and Indian Oceans. Journal of Climate, 11(7), 1685-1702. doi: 10.1175/1520-0442(1998)011<1685:IVOSFA $\rangle 2.0$. CO $; 2$

Sprintall, J., \& Tomczak, M. (1992). Evidence of the Barrier Layer in the Surface Layer of the Tropics ocean surface mixed layer generally denotes a quasi- kinetic energy and potential energy processes mentioned its degree state. Journal Of Geophysical Research, 97(C5), 7305-7316.

Susanto, R. D., Gordon, A. L., \& Zheng, Q. (2001). Upwelling along the coasts of Java and Sumatra and its relation to ENSO. Geophysical Research Letters, 28(8), 1599-1602. doi: 10.1029/2000GL011844

Syamsudin, F., Kaneko, A., \& Haidvogel, D. B. (2004). Numerical and observational estimates of Indian Ocean Kelvin wave intrusion into Lombok Strait. Geophysical Research Letters, 31 (24), 1-4. doi: 10.1029/2004GL021227

Webber, B. G. M., Matthews, A. J., \& Heywood, K. J. (2010). A dynamical ocean feedback mechanism for the Madden-Julian Oscillation. Quarterly Journal of the Royal Meteorological Society, 136(648), 740-754. doi: 10.1002/qj.604

Webber, B. G. M., Matthews, A. J., Heywood, K. J., Kaiser, J., \& Schmidtko, S. (2014, jun). Seaglider observations of equatorial Indian Ocean Rossby waves associated with the Madden-Julian Oscillation. Journal of Geophysical Research: Oceans, 119(6), 3714-3731. Retrieved from http://doi.wiley.com/ 10.1002/2013JC009657 doi: 10.1002/2013JC009657

Webber, B. G. M., Matthews, A. J., Heywood, K. J., \& Stevens, D. P. Ocean Rossby waves as a triggering mechanism for primary Madden-Julian events. Quarterly Journal of the Royal Meteorological Society, 138(663), 514527. doi: 10.1002/qj.936

Wheeler, M., \& Kiladis, G. N. (1999). Convectively Coupled Equatorial Waves: Analysis of Clouds and Temperature in the Wavenumber-Frequency 
Domain. Journal of the Atmospheric Sciences, 56(3), 374-399. doi: 10.1175/1520-0469(1999)056<0374:CCEWAO $\rangle 2.0 . \mathrm{CO} ; 2$

Wheeler, M., Kiladis, G. N., \& Webster, P. J. (2000). Large-scale dynamical fields associated with convectively coupled equatorial waves. Journal of the Atmospheric Sciences, 57(5), 613-640. doi: 10.1175/1520-0469(2000)057〈0613: LSDFAW $>2.0 . \mathrm{CO} ; 2$

Wyrtki, K. (1962). The upwelling in the region between Java and Australia during the south-east monsoon. Australian journal of marine and freshwater research, 13, 217-225. Retrieved from http://hdl.handle.net/102.100.100/329922 ?index=1 doi: procite:751a1915-67ee-42ba-9121-4eaf8d1b8985

Zhang, C. (2005). Madden-Julian Oscillation. Reviews of Geophysics, 43(2), 1-36. Retrieved from http://140.90.101.29/products/precip/CWlink/MJO/MJO\{\ _\}1page\{\_\}factsheet.pdfhttp://doi.wiley.com/10.1029/2004RG000158 doi: $10.1029 / 2004 R G 000158$ 

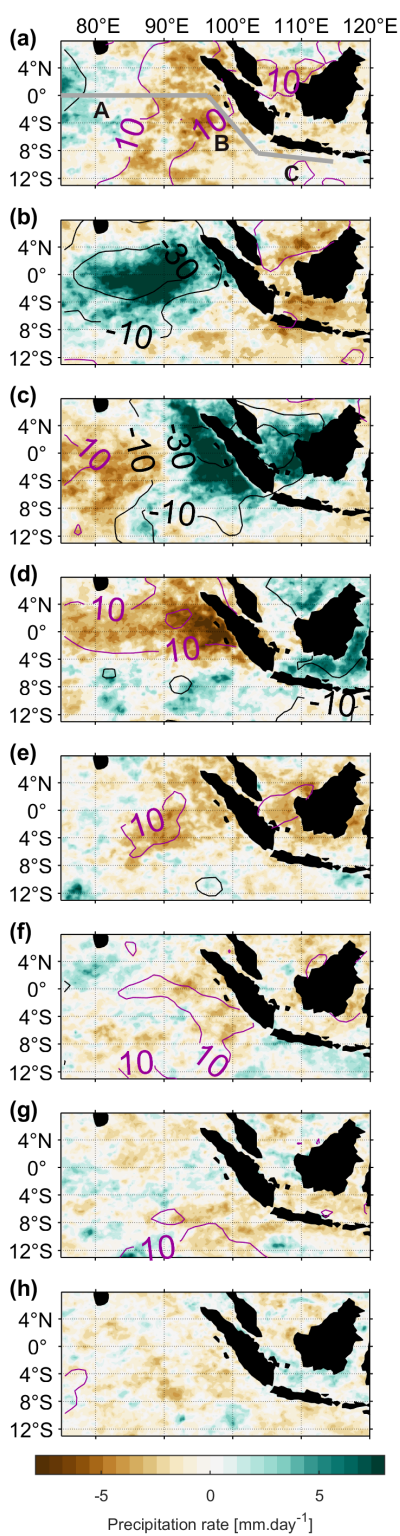
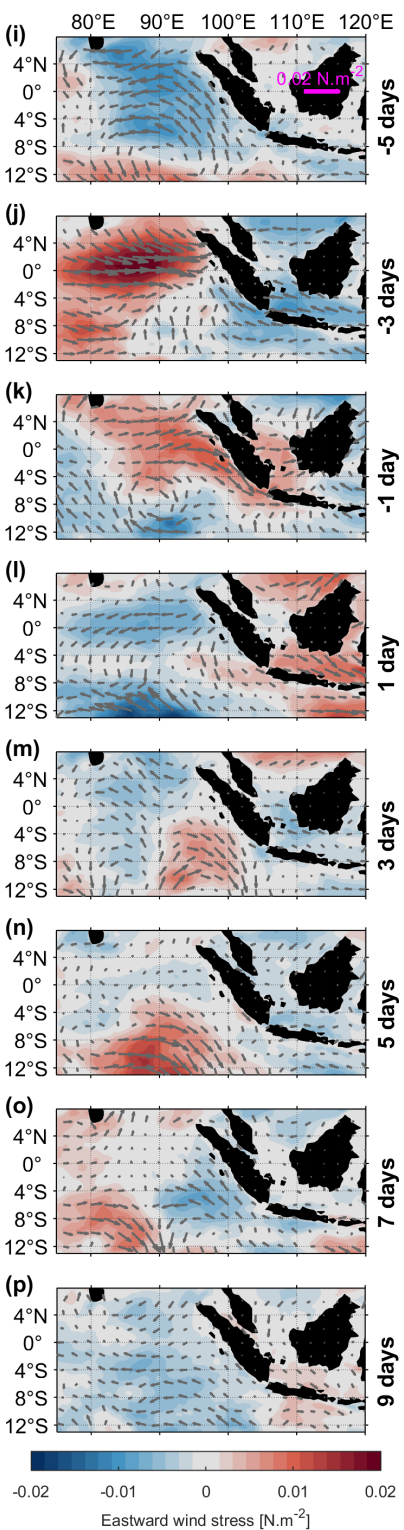

Figure 1. Lagged composite anomalies of: $(\mathrm{a}-\mathrm{h})$ precipitation rate $\left(\mathrm{mm} \mathrm{day}^{-1}\right.$, colour shaded) and net heat flux (contour interval is $20 \mathrm{~W} \mathrm{~m}^{-2}$; negative contours are black, positive contours are magenta, and the first positive contour is at $\left.10 \mathrm{~W} \mathrm{~m}^{-2}\right)$; $(\mathrm{i}-\mathrm{p})$ eastward wind stress $\left(\mathrm{N} \mathrm{m}^{-2}\right.$; colour shaded) and wind stress vectors $\left(\mathrm{N} \mathrm{m}^{-2}\right.$; reference vector in panel $\mathrm{i}$ ), for strong solitary CCKW events passing the $110^{\circ} \mathrm{E}$ base point at lag 0 . 

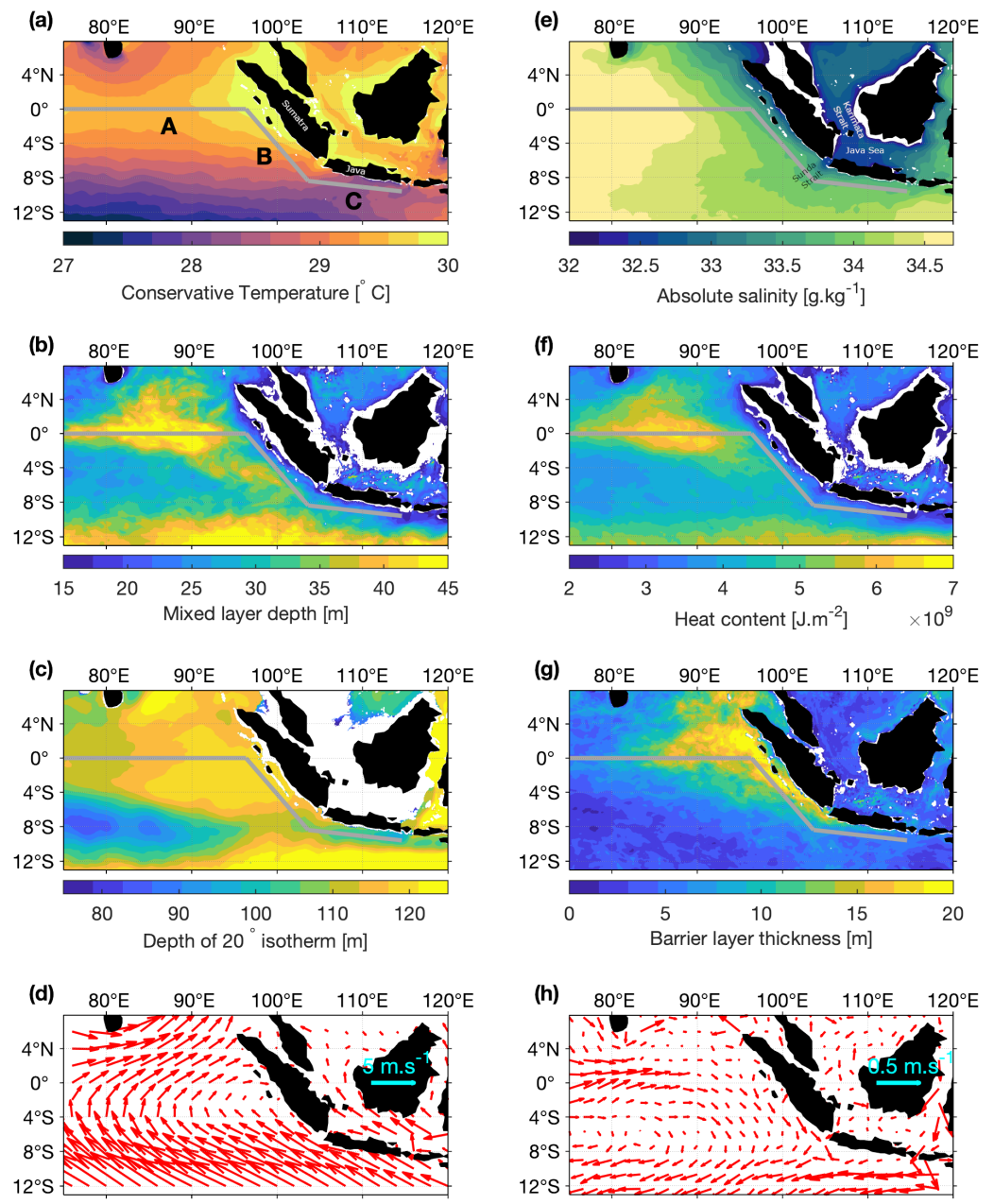

Wind speed $\left[\mathrm{m} \cdot \mathrm{s}^{-1}\right]$

Current speed $\left[\mathrm{m} \cdot \mathrm{s}^{-1}\right]$

Figure 2. Precursor fields (composite means over lags -10 to -6 days, relative to CCKW events crossing $110^{\circ}$ at lag 0 days) of (a) oceanic conservative temperature $\left({ }^{\circ} \mathrm{C}\right),(\mathrm{b})$ mixed layer depth (m), (c) depth of the $20^{\circ} \mathrm{C}$ isotherm, (d) surface wind vectors $\mathrm{m} \mathrm{s}^{-1}$, (e) absolute salinity $\left(\mathrm{g} \mathrm{kg}^{-1}\right)$, (f) heat content $\mathrm{J} \mathrm{m}^{-2}$, (g) barrier layer thickness (m) and (h) surface ocean current vectors $\mathrm{ms}^{-1}$. The grey lines shows the propagation path of oceanic Kelvin waves and consist of three sections labelled in panel (a): section A along the Equator from $60^{\circ} \mathrm{E}$ to $96.35^{\circ} \mathrm{E}$; section $\mathrm{B}$ along the coast of Sumatra, and section C along the coast of Java. 

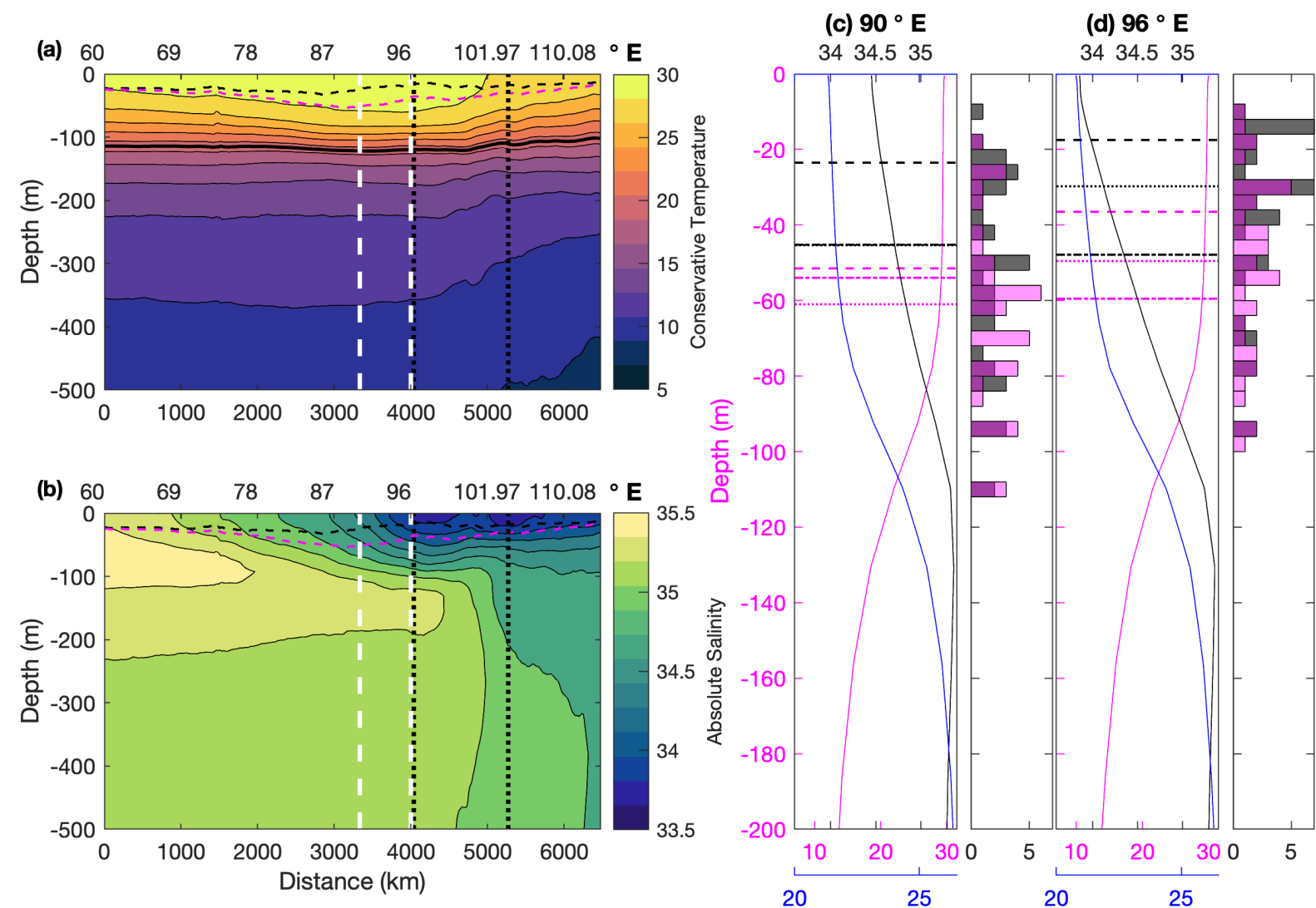

Figure 3. Precursor fields (defined as in Fig. 2) of (a) conservative temperature $\left({ }^{\circ} \mathrm{C}\right.$; contoured between $15^{\circ} \mathrm{C}$ and $29^{\circ} \mathrm{C}$, every $2^{\circ} \mathrm{C}$, with extra level at $20^{\circ} \mathrm{C}$ (thick line). (b) absolute salinity $\left(\mathrm{g} \mathrm{kg}^{-1}\right.$; contoured between $32 \mathrm{~g} \mathrm{~kg}^{-1}$ and $35.4 \mathrm{~g} \mathrm{~kg}^{-1}$ every $0.2 \mathrm{~g} \mathrm{~kg}^{-1}$ ) along vertical ocean sections A, B and C (limit of section indicated by vertical black dotted lines; see map in figure 2a for geographic reference). Bottom horizontal axis shows distance from the $60^{\circ} \mathrm{E}$ meridian and top horizontal axis indicates longitude. Black and magenta dashed lines indicate mixed layer depth (MLD) and isothermal layer depth (ILD) calculated from the averaged profile, respectively. White vertical dashed lines indicate the position of profiles at $90^{\circ} \mathrm{E}$ and $96^{\circ} \mathrm{E}$. Panels (c) and (d) show profile of conservative temperature $\left({ }^{\circ} \mathrm{C}\right.$; magenta), absolute salinity $\left(\mathrm{g} \mathrm{kg}^{-1}\right.$; black) and potential density $\left(\mathrm{kg} \mathrm{m}^{-3}\right.$; blue) at $90^{\circ} \mathrm{E}$ and $96^{\circ} \mathrm{E}$, respectively. Black and magenta horizontal lines indicate MLD and ILD, calculated from the averaged M10-M6 composite profiles (dashed lines), from averaging the M10-M6 composite values of MLD and ILD (dotted lines), and from averaging the climatological daily MLD and ILD values (dotted-dash line). Histograms show the daily MLD (black) and ILD (magenta) values at day zero for all solitary events. ILD (magenta) histogram is presented with a 50\% colour transparency level and plotted on top of the MLD histogram. 


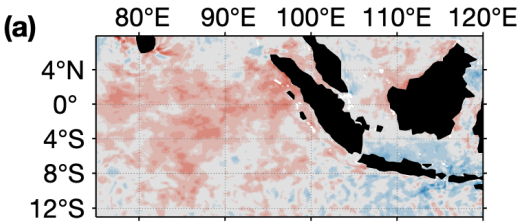

(b)

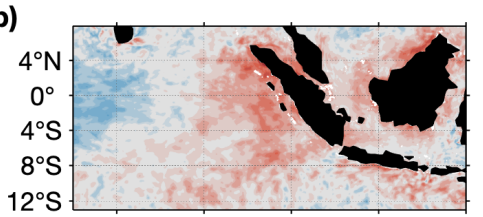

(c)

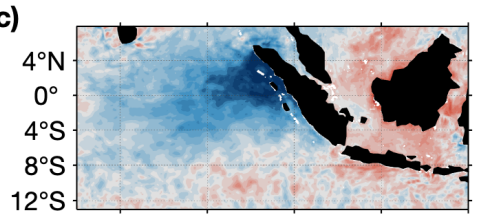

(d)

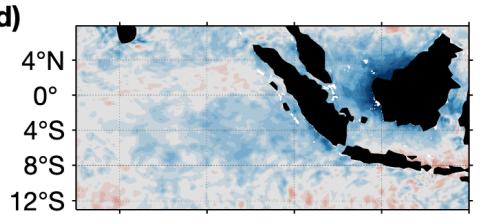

(e)

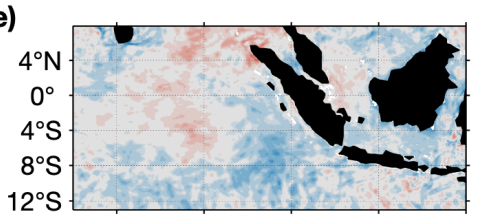

(f)

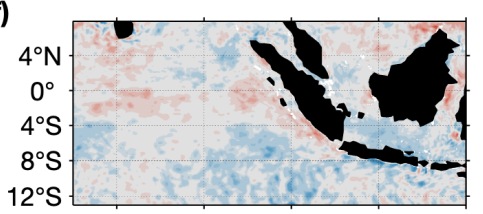

(g)

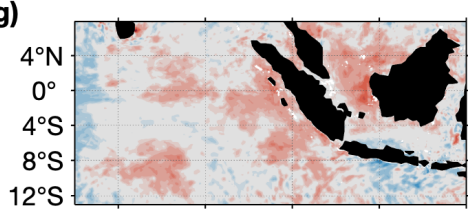

(h)

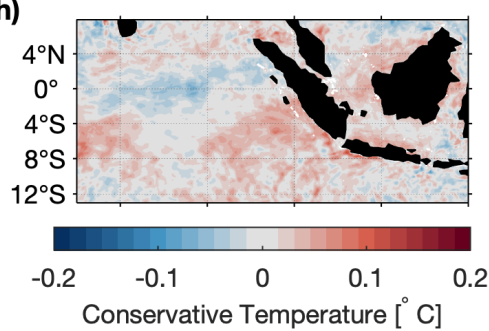

(i)

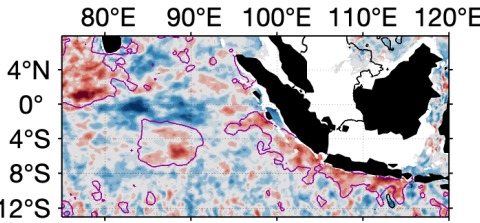

(j)

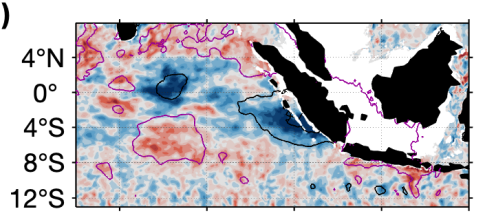

(k)

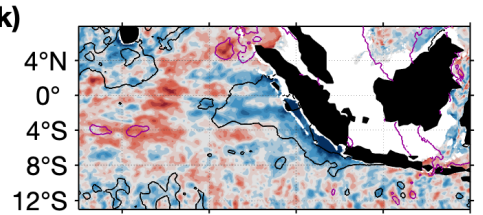

(I)

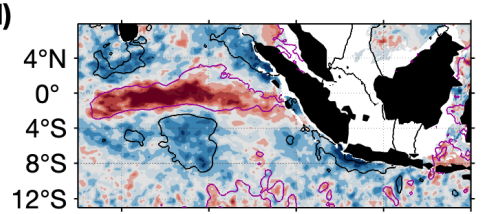

(m)

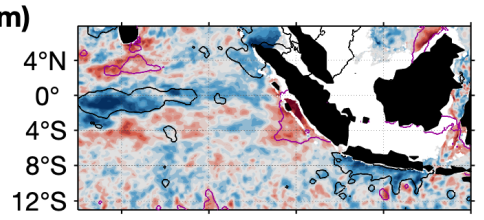

(n)

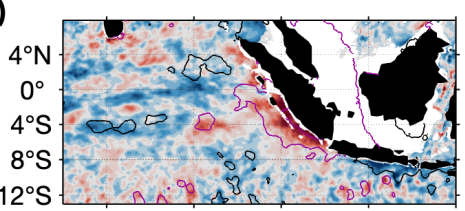

(o)

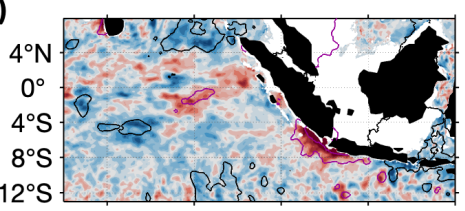

(p)

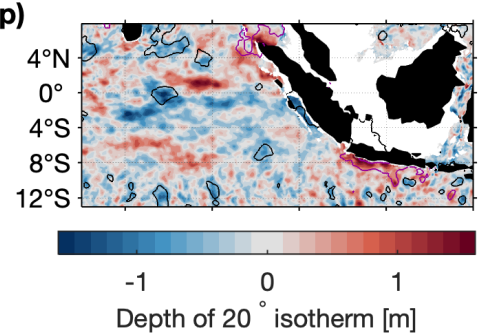

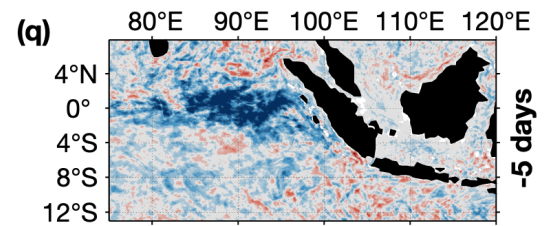

(r)

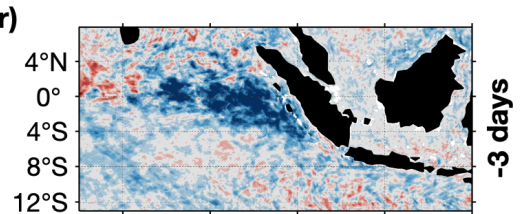

(s)

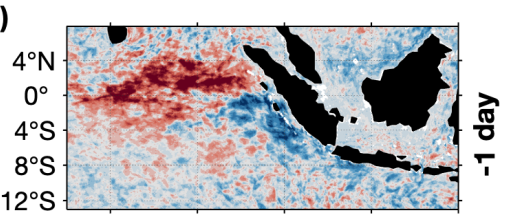

(t)

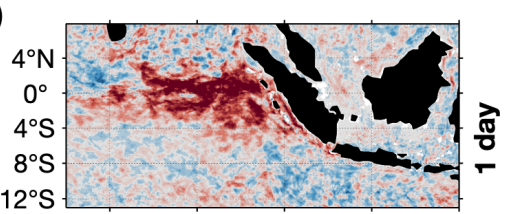

(u)

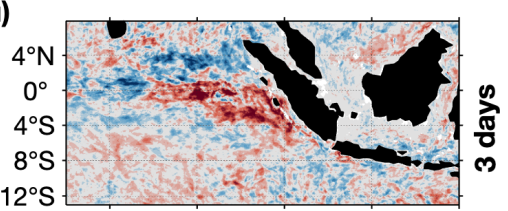

(v)

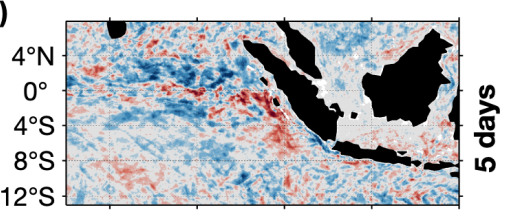

(w)

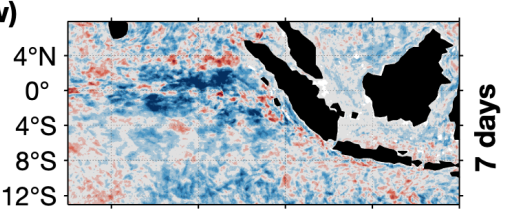

(x)

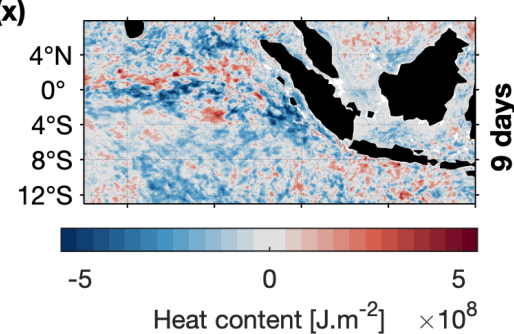

Figure 4. Maps of daily lagged composite anomalies of (a-h) sea surface conservative temperature $\left({ }^{\circ} \mathrm{C}\right.$; colour shaded); (i-p) depth of $20{ }^{\circ} \mathrm{C}$ isotherm (m; colour shaded) and sea surface height $(\mathrm{m}$; contoured at the intervals $-0.01,-0.003,0.003,0.01) ;(\mathrm{q}-\mathrm{x})$ heat content of the mixed layer $\left(\mathrm{J} \mathrm{m}^{-2}\right.$; colour shaded) for CCKW strong solitary events passing at $110^{\circ} \mathrm{E}$ at lag 0 . For all panels negative values are contoured in black lines and positive values in magenta lines. 

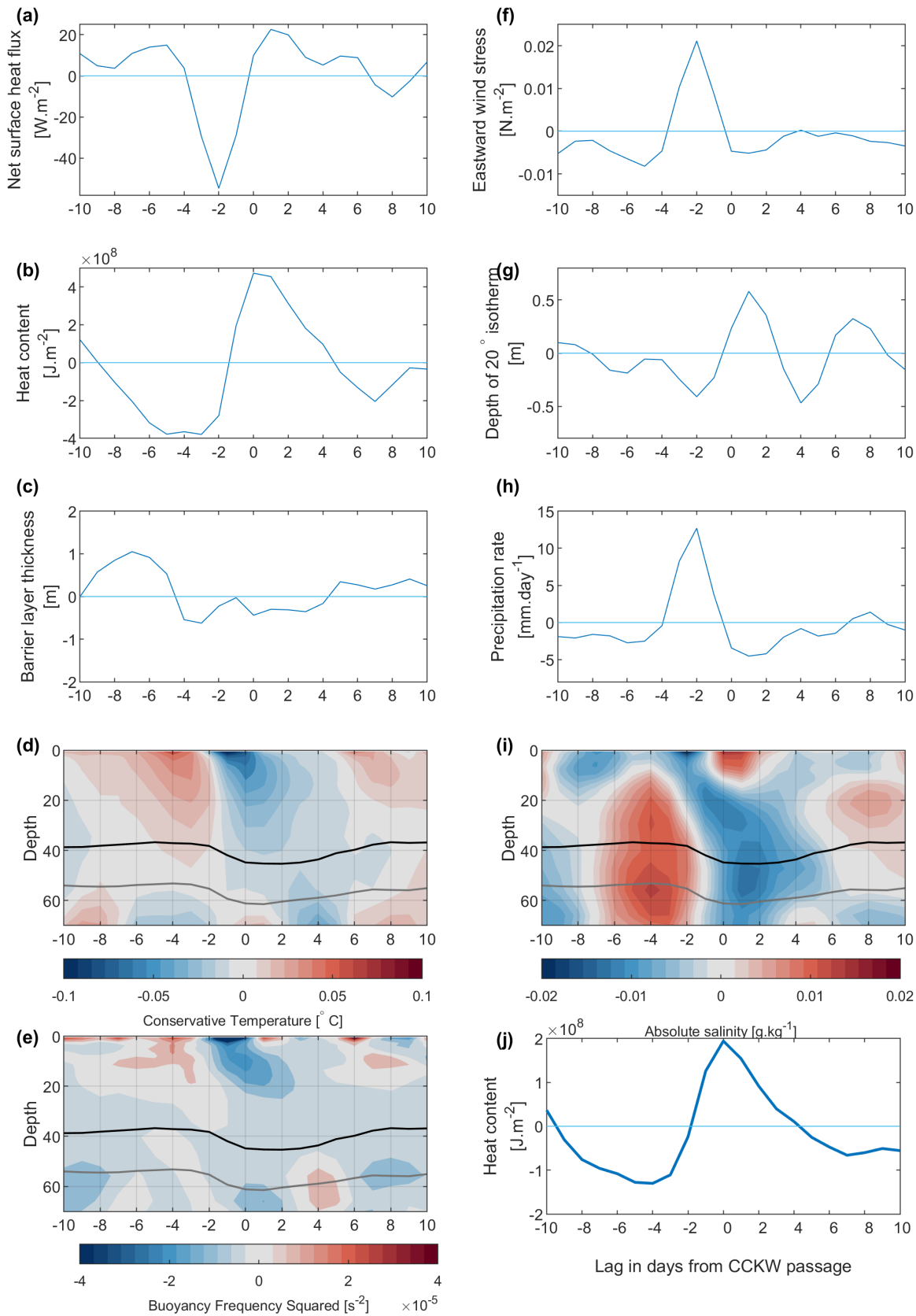

Figure 5. Daily composite anomalies averaged over a box in the equatorial Indian Ocean $\left(2.5^{\circ} \mathrm{N}-2.5^{\circ} \mathrm{S}, 90^{\circ} \mathrm{E}-95^{\circ} \mathrm{E}\right)$ for (a) net surface heat flux, (b) heat content, (c) barrier layer thickness, (d) conservative temperature, (e) buoyancy frequency squared, (f) eastward wind stress, (g) depth of $20^{\circ} \mathrm{C}$ isotherm, (h) precipitation rate and (i) absolute salinity. In panel (d), mixed layer depth (MLD) is shown by the black line, and isopycal layer depth (ILD) by the gray line. In panel $(\mathrm{j})$, daily composites of heat content anomaly are shown averaged over the larger domain $8^{\circ} \mathrm{S}-4^{\circ} \mathrm{N}, 75-100^{\circ} \mathrm{E}$. 

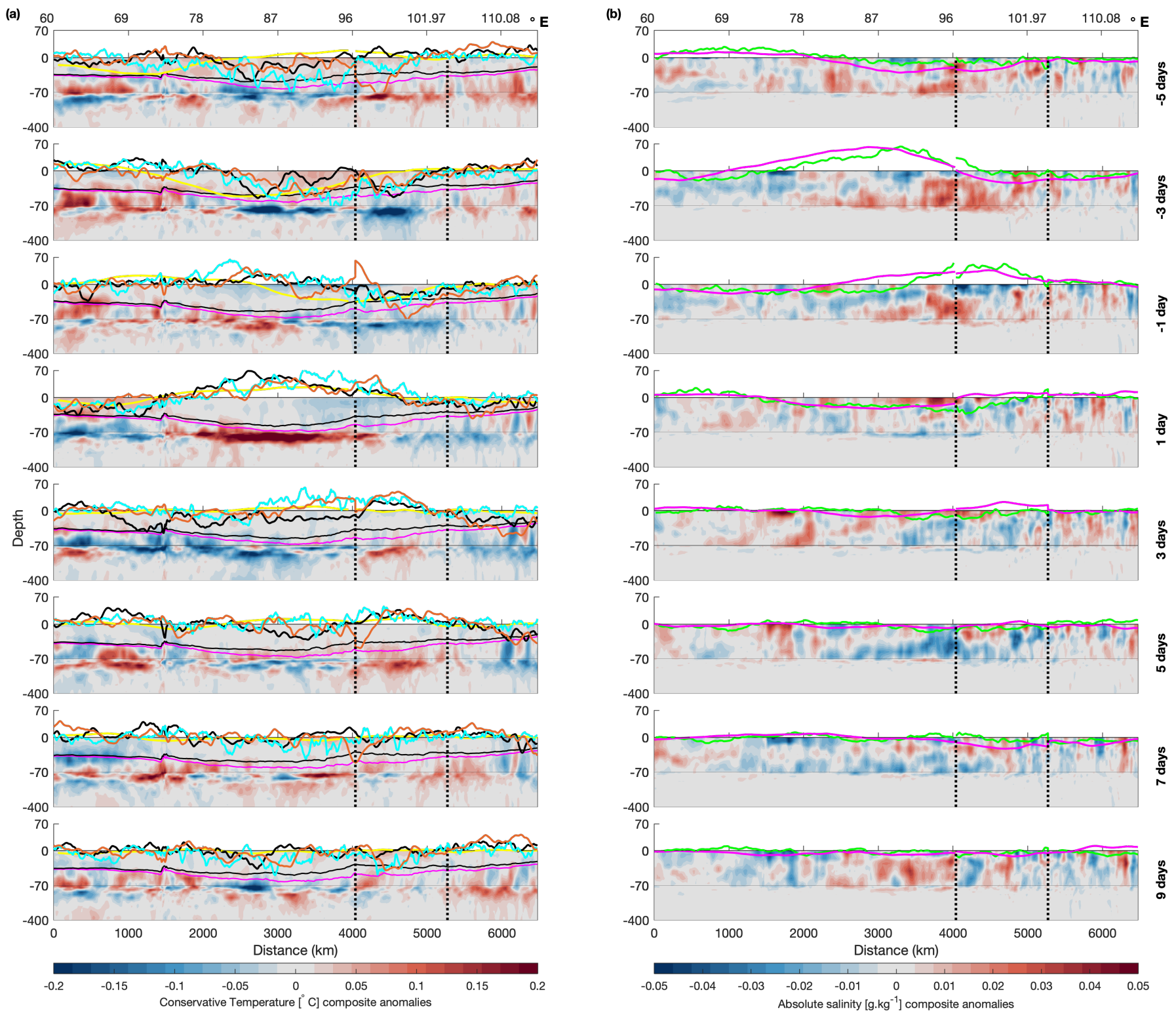

Figure 6. Vertical section (sections A, B and C, limits indicated by vertical dotted line; see map in Figure 2) of daily lagged composite anomalies at lags $-5,-3,-1,+1,+3,+5,+7$ and +9 of (a) conservative temperature $\left({ }^{\circ} \mathrm{C}\right)$ and (b) absolute salinity $\left(\mathrm{g} \mathrm{kg}^{-1}\right)$ for CCKW strong solitary events passing at $110^{\circ} \mathrm{E}$. In panels (a), daily composites of MLD and ILD total fields are shown by black and magenta lines, respectively. Along section daily composites of anomaly fields of downward net heat flux $\left(\times 2 ; \mathrm{W} \mathrm{m}^{-2}\right.$; yellow line $)$, depth of $20^{\circ} \mathrm{C}$ isotherm $(\times 20 ; \mathrm{m}$; black line, heat content $\left(\times 10^{-7} ; \mathrm{J} \mathrm{m}^{-2} ;\right.$ cyan line $)$ and ocean velocity parallel to the sections $\left(\times 3.10^{3} ; \mathrm{m} \mathrm{s}^{-1}\right.$; brown line). In panels (b) it is shown the along section daily composites of anomaly fields of precipitation $\left(\times 4.5 ; \mathrm{mm} \mathrm{day}^{-1} ;\right.$ green line $)$ and wind stress parallel to the sections $\left(\times 2.5 .10^{3} ; \mathrm{N} \mathrm{m}^{-2}\right.$ ; magenta line). Note that the scale of the vertical axis is different for the range from 70 to -70 and that from -400 to -70 . 

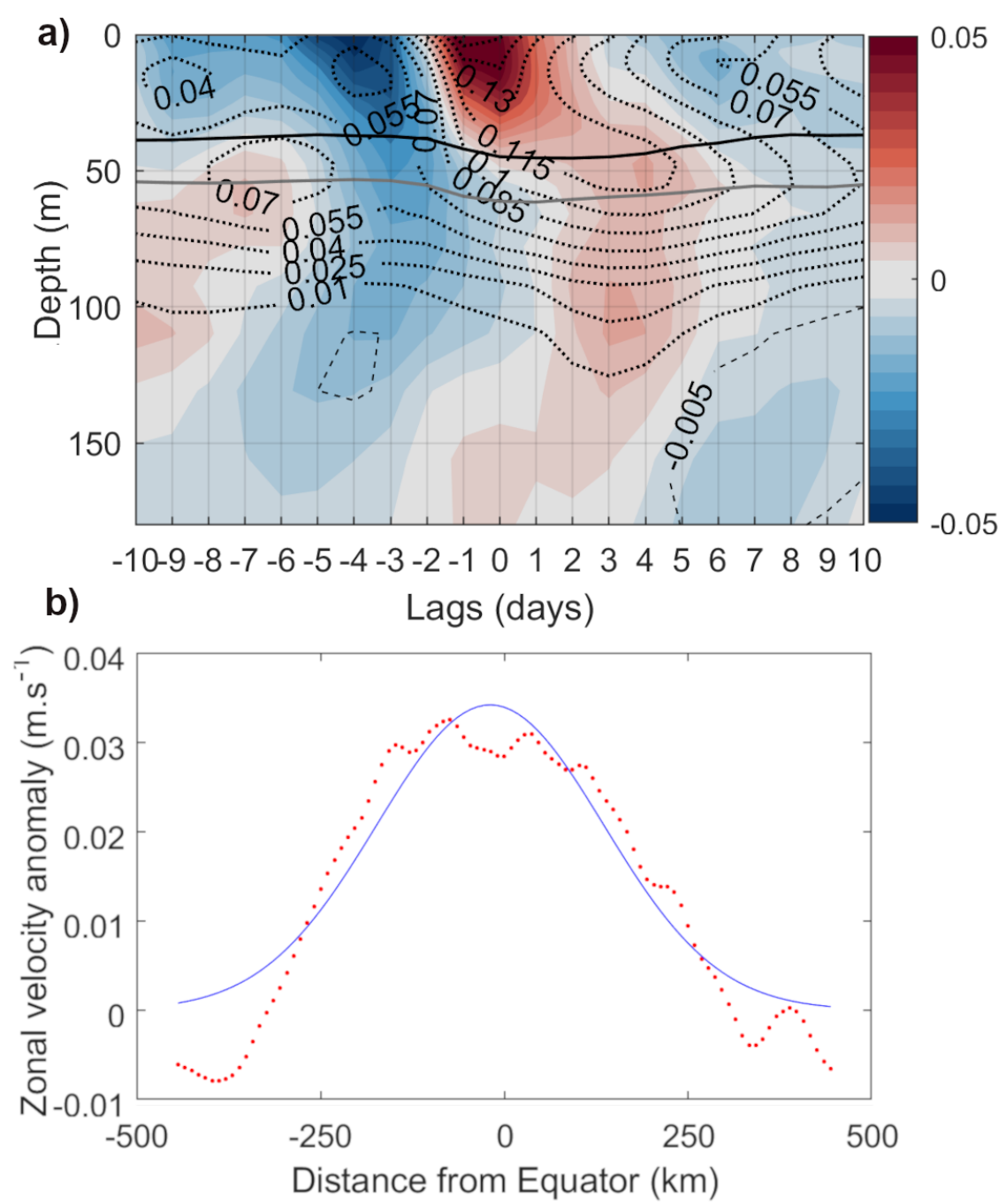

Figure 7. (a) Zonal velocity $\left(\mathrm{m} \mathrm{s}^{-1}\right)$ composite anomalies (colour shading), and total field (dotted line contours), averaged over $2.5^{\circ} \mathrm{S}-2.5^{\circ} \mathrm{N}, 90-95^{\circ} \mathrm{E}$. Thick black and gray lines indicates the MLD and ILD respectively. (b) Zonal velocity anomalies $\left(\mathrm{m} \mathrm{s}^{-1}\right.$; red circles) averaged between $100-200 \mathrm{~m}$ for lag +3 days using $90^{\circ} \mathrm{E}$ as the CCKW composite base point between $4^{\circ} \mathrm{N}-4^{\circ} \mathrm{S}$. Data are 90 -day high-pass filtered. The blue line shows the best least-square fit to a theoretical Kelvin wave solution. 

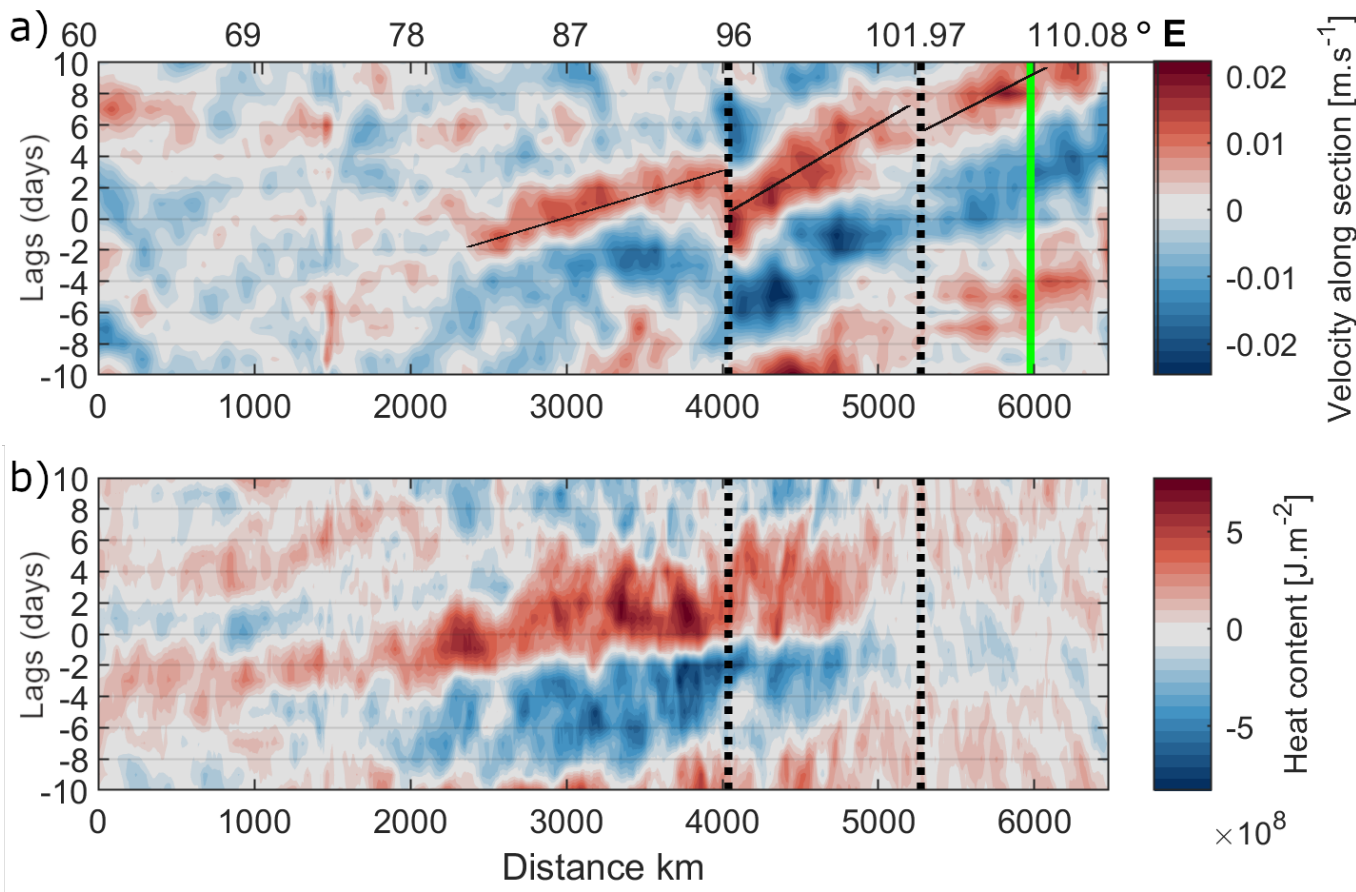

Figure 8. Hovmöller diagram for daily composite anomalies for (a) zonal velocity $\left(\mathrm{m} \mathrm{s}^{-1}\right)$

(60-200 m average), (b) depth of $20^{\circ} \mathrm{C}$ isotherm (m) and (c) heat content $\left(\mathrm{J} \mathrm{m}^{-2}\right)$ along sections A, B and C (section limits indicated by vertical dotted lines; see map in Figure 2). Vertical green line indicates base point location for composite calculations. 